\title{
Blame-Game Politics in a Coalition Government ${ }^{1}$
}

\author{
Arnaud Dellis* \\ * University of Hawaii - Manoa, Department of Economics, 2424 Maile Way, \\ Honolulu, HI 96822, USA \\ E-mail: adellis@hawaii.edu
}

Version: August 2005

\begin{abstract}
An important question in political economics concerns delays in the adoption of socially beneficial reforms. The present paper explores this issue in the context of a representative democracy where the government is a coalition and citizens observe neither the decisionmaking process, nor the policy preferences of the politicians. It shows that a governing party favoring a reform may nonetheless choose to veto its adoption and blame its coalition partners for the non-adoption. This is referred to as blame-game politics. The rationale for playing such a game is to prevent some parties from acquiring a better reputation as supporters of the reform. At a more general level, the argument applies to situations where several agents, whose types are private information have each to take an action while the principal observes only the aggregate outcome.
\end{abstract}

Key Words: Reputation; Delayed adoption of reforms; Coalition Government. JEL Classification: D7; D82; H0.

\section{INTRODUCTION}

There is a large body of literature that studies delays in the adoption of reforms. But surprisingly enough only a relatively small portion of it looks at that problem in the context of coalition governments, which however are well-known for the difficulty they have in quickly passing reforms. ${ }^{2}$ Now there is nothing really puzzling in the delayed adoption of a reform that benefits only a minority. What is baffling is when the reform benefits a majority, and even more if it is also socially desirable. The present work considers such a (welfare-enhancing) majority-preferred reform, and provides an explanation for why a coalition government may delay the adoption of such a reform, even if all its members would, as citizens, benefit from the reform.

The positive economic literature has yielded two explanations for the delayed adoption of reforms by coalition governments. One explanation is the instability of those governments, which implies that coalition members do not have enough incentives to cooperate. For example consider a coalition member who has been proposed the following deal: if he let pass the currently-debated reform that hurts him but benefits his coalition partner, the latter commits that he will not veto the adoption of another reform that benefits our coalition member but hurts his coalition partner. Now our coalition member will be very reluctant to accept this

\footnotetext{
${ }^{1}$ I would like to thank Steve Coate for his invaluable support and comments. I am also grateful to Georges Casamatta, Ted O’Donoghue, Christoph Vanberg, and seminar participants, for helpful comments.

${ }^{2}$ For example Roubini and Sachs (1989) and Grilli et al. (1991) show that often coalition governments are associated with large budget deficits, which they interpret as suggesting the difficulty those governments have of quickly enacting reforms.
} 
deal if he anticipates that the coalition is going to break soon. Indeed by the time his reform will be on the agenda, there is a good chance that the government will no longer be in office. The second explanation is that cabinet ministers may have difficulties reaching an agreement on a reform because of ideological differences on that issue or conflicts on how to share the cost of the reform. For example, a conservative politician may veto a tax increase, especially one which is targeted towards the electorate he represents.

One feature those two explanations share in common is that they both rely on the heterogeneity of preferences among coalition members. Hence they cannot explain the delayed adoption of a reform considered as desirable by all cabinet members, a situation that we sometimes observe. For example between 1997 and 2002 the French government was divided between Prime Minister Jospin and President Chirac, both being responsible for the policies implemented. By the end of their term in office, homeland security reforms - considered as desirable by a vast majority of the population, and on which both Jospin and Chirac seemed to agree - had not yet been adopted. Also, in 1999 a new coalition government was formed in Belgium. At that time one prominent issue on the agenda was a reform of the judicial system, reform which was asked by an overwhelming majority of the population and on the desirability of which all coalition members agreed. Four years later, just before the next general election, the reform had not yet been adopted. Hence we are left without any explanation for why a stable coalition government sometimes delays the adoption of a reform that benefits all its members as well as a majority of the population. The contribution of the present paper is to fill this gap.

But before going further, it is worth making two observations. First it is commonplace to hear politicians blaming their fellows for the non-adoption of a reform. This had been the case in the two examples discussed above. Indeed during the 2002 presidential election campaign in France Chirac blamed Jospin for the nonadoption of homeland security reforms. And at the beginning of May 2003, two weeks before the general election, the two major parties in the Belgian coalition government were blaming each other for the non-adoption of the reform of the judicial system. A second observation concerns the rules under which coalition governments traditionally operate. In a large number of countries where the government is a coalition, the adoption of a decision requires either unanimity or a consensus among cabinet members. ${ }^{3}$ This means that each governing party has the power to block the adoption of a reform. Another rule under which coalition governments usually operate is collective responsibility. This means that all cabinet members bear the responsibility for the policies that are (or are not) adopted. It also implies that, while in office, a minister is not supposed to publicly voice his opposition to the cabinet's decisions. As a result, citizens observe the policy outcome but not the decision process. ${ }^{4}$ Hence voters are unable to determine who among the coalition members is responsible when deadlock arises. ${ }^{5}$

\footnotetext{
${ }^{3}$ For a cross-country study of coalition governments, see Laver and Shepsle (1994) or Muller and Strom (2000).

${ }^{4}$ This is reinforced by the fact that there is rarely any vote in cabinet, implying that no record of the deliberations is kept.

${ }^{5}$ This point is nicely illustrated by Gisela Stuart (MEP) who said about the Council of the European Union: "Right now, if my prime minister goes to Brussels and make decisions behind closed doors, I as a parliamentarian cannot hold him to account because I only know the outcome, I don't know the process ... It's the same with the ministers. They can tell me anything" (New York Times, 16 June 2003).
} 
Based upon those observations, this paper shows that a member of a stable and ideologically homogeneous coalition who would benefit from a reform may nonetheless choose to veto its adoption. The argument runs as follows. Consider a situation where citizens are not perfectly informed about politicians' preferences for a reform and where a majority of voters want that reform to be implemented. One governing party may strategically decide to veto the adoption of the reform and blame its coalition partners for the deadlock. Citizens then observe the reform not having been implemented but are unable to determine with certainty where responsibility lies. The motivation underlying such a strategy is to damage the reputation some parties have of supporting the reform. By doing so, a party can increase its chances of being in the next government. This strategy is referred to as blame-game politics. ${ }^{6}$

The paper identifies three reasons why a party would want to play the blamegame. The first is related to the issue salience in the electoral debate. A party may be willing to keep an issue salient (even one on which the party is electorally at a disadvantage, as we shall see). And one way to do so is by delaying, until after the next election, the adoption of any reform associated with that issue. The second reason applies to situations where a politician can hide his stance on an issue. The third reason concerns a politician who is trying to enhance his bargaining power in the coalition formation process. This occurs when he can either keep an issue salient for the other politicians, thus forcing them to take him as a coalition partner because of his stance on that issue, or get a higher vote share relative to the other parties, thus increasing its chances of being appointed as the government formateur.

The paper also shows that having a small single-issue party (like the Green party), in or out of office, does not necessarily help their cause. Indeed that or another party may want to play the blame-game in order to keep this issue salient in the next election, or in the formation of the next coalition government.

The remainder of the paper is organized as follows. Section 2 briefly reviews some related literature. Section 3 outlines the model, and section 4 studies equilibrium policy choices. Section 5 discusses the results, and section 6 concludes.

\section{RELATED LITERATURE}

This paper is related to the political economy literature on delayed adoption of socially beneficial reforms. Following Drazen (2000), I classify those models into three categories. The first strand (often associated with Olson (1982)) considers policy decisions made by a powerful group who has a vested interest in keeping the status quo. The second strand is based on the public-good nature of the reform. In their seminal paper, Alesina and Drazen (1991) consider a war-of-attrition model where each group waits for the other one to concede and accept to bear a larger share of the costs associated with the reform. Their argument hinges on asymmetric information as to how costly the reform is for each group as well as the need for unanimity to pass the reform. Consensus and uncertainty are also key in our analysis but, in contrast to theirs, the reform is costless for the governing parties. The third strand is based on the uncertainty about individual benefits. Laban and Sturzenegger (1994) show that the adoption of a socially beneficial reform

\footnotetext{
${ }^{6}$ Note that blame-game politics provides a possible explanation for the two examples discussed above. However it is worth noting that it is not possible to ascertain it is the correct explanation. Indeed no politician ever claimed having played such a game since that would defeat its most elementary objective, namely to masquerade.
} 
can be delayed by rational voters, despite the fact that economic conditions are deteriorating over time. This status quo bias relies on ex ante uncertainty about who will gain and who will lose from the adoption of the reform. ${ }^{7}$ This contrasts with the present model where individuals know with certainty whether or not they will gain from the reform and where there is no such thing as a deterioration of the status quo over time. Note that a common feature to those three strands is a conflict of interests, i.e. adopting the reform today instead of tomorrow is (or is expected to be) harmful for some of the policymakers. Hence, in terms of results, the present model contrasts with those papers in that it generates delays in the adoption of reforms that benefit all policymakers (as well as a majority of their respective electorates), a result we cannot get in those previous contributions.

At a more general level, the current analysis is also related to the literature on reputational and career concerns initiated by Fama (1980), and formalized by Holmstrom (1982a). The basic idea is that if an agent's competence is incompletely known, the principal can use past outcomes in order to draw some inferences about the agent's ability, and then forecast future performances. The agent, being concerned about her future career and anticipating that her current decisions may signal her competence, then takes actions that will enhance her reputation.

A number of other papers have subsequently looked at situations where those reputational and career concerns lead to the adoption of inefficient actions. One strand of this literature considers situations where an agent adopts an inefficient action in order to preserve or build-up a reputation. ${ }^{8}$ The present analysis departs from those models in that the inefficiency comes instead from politicians trying to damage reputations. Another strand of this literature has focused on situations where an incumbent manipulates a state variable in an inefficient way so as to make his fellow politicians less attractive to the voters and thus increase his own probability of reelection. ${ }^{9}$ While strategic manipulation is also key here, current policy decisions have an impact on citizens' voting behavior not only because they affect constraints on future governments, but also because they provide some information about parties' policy preferences. Finally, the present analysis is also related to Holmstrom (1982b) who studies moral hazard in teams. As in this paper, he shows that in a multi-agent setting, people can cover up improper actions behind the uncertainty as to who is at fault. However, he also argues that group penalties are sufficient to discipline agents, a result which no longer holds here. ${ }^{10}$

This analysis is also related to the literature on sabotage. Lazear (1989) considers a situation where a manager observes each workers' output and rewards them on the basis of their relative performance. He shows that such rank-order tournaments discourage cooperation among workers and can then lead to sabotage, workers taking actions that adversely affect others' output. Relative performance

\footnotetext{
${ }^{7}$ Their model is a dynamic version of Fernandez and Rodrik (1991), the latter showing that uncertainty about the identity of gainers and losers can lead to a socially beneficial reform not being undertaken, even though it would receive a large political support once introduced. However, while Fernandez and Rodrik's model can explain non-adoption of reforms, it cannot generate delays. Indeed, if the reform is not enacted today, uncertainty about the distribution of gains and losses still holds and with it the source of the non-adoption. As a result, if the reform is not implemented today, it will not be implemented tomorrow.

${ }^{8}$ See Rogoff and Sibert (1988), Rogoff (1990), Coate and Morris (1995), Holmstrom and Ricart I Costa (1986), Prendergast and Stole (1996), Morris (2001) and Scharfstein and Stein (1990).

${ }^{9}$ See Aghion and Bolton (1990), Milesi-Ferretti and Spolaore (1994) and Besley and Coate (1998).

${ }^{10}$ The reason for this difference is that the threat of group penalties is credible in Holmstom (1982b) but not here.
} 
(i.e. parties' reputations) is also key here. However the relation to this literature stops here, the present analysis differing in at least two important ways. First, citizens observe only the 'aggregate outcome' of the coalition, not the 'output' of each party. Second, in terms of outcome, vetoing the adoption of the reform affects the output of all coalition members, while only the output of the worker who is the victim of sabotage is affected.

Finally, Groseclose and McCarty (2001) develop a model that has some features in common with our analysis. In their paper, a one-member Congress submits a bill to a president who can either sign or veto it. The electorate is uninformed about the president's policy preferences but can learn about them from the veto decision. They show that when the government is divided, the Congress may propose a bill it knows will be vetoed in order to damage the reputation of the president by making him appear more extremist than he actually is. ${ }^{11}$

\section{THE MODEL}

The model considers a two-period game in which a government has to decide in each period $t \in\{1,2\}$ on two issues: the level of public spending and a discrete reform such as liberalizing trade, building a new road or signing a treaty. ${ }^{12}$ Let $g_{t} \in$ $[0,1]$ denote the level of public spending in period $t$ and $r_{t}$ the status of the reform, with $r_{t}=1(0$, resp.) meaning that the reform is (is not, resp.) in effect in period $t$. At the beginning of the first period, there is a status quo level of public spending (e.g. the level implemented by the previous government). A coalition government has then to decide which level of public spending to adopt and whether to pass the reform. The decision-making process is sequential, the government first deciding on the reform issue and then on public spending. ${ }^{13}$ Each party in the coalition has veto power and thus, for each issue, a policy different from the status quo is implemented only if all coalition members agree on it. Citizens observe the policy outcome $p_{1}=\left(g_{1}, r_{1}\right)$ but not the individual decision of each incumbent. At the end of the period, an election is held to select a new government and the first-period

\footnotetext{
${ }^{11}$ Their analysis differs from the present one in several ways. First, they try to explain the use of the presidential veto. As a result, they consider a one-period model in a presidential regime. The current analysis applies rather to coalition governments. Moreover, this paper tries to explain delays in the adoption of socially beneficial reforms which, by definition, cannot occur in a oneperiod framework. Second, they assume citizens observe the bill that has been submitted and the president's veto decision. This leads them to conclude that the decision-making process should sometimes be kept secret. The present model demonstrates that this may not be true, since the non-observability of the decision process allows politicians to cover up inefficient actions. Third, the Congress and the president have heterogenous preferences while here, coalition partners may share the same preferences for the reform. Finally, only the Congress can play the blame-game and only citizens' approval of the president, not of the congressmen, matters. In this paper, all decision-makers can play the blame-game and all care about their reputation. Hence, politicians take into account the negative impact of vetoing the adoption of the reform on the reputation of all parties, including their own.

${ }^{12}$ The model considers a reform that can be either implemented or rejected. But the same argument would apply to a continuous policy variable. For example, a party may agree only on a too moderate fiscal stabilization program and then blame its coalition partners for not having been able to pass a better one.

${ }^{13}$ The order in which the government decides on the different issues is not key for the argument; the same results as those presented below can be obtained (under nearly identical conditions on incumbents' preferences) if they first choose the level of public spending and then decide on the reform issue. In the same time, the government deciding simultaneously on both issues (i.e. bundling them into an 'omnibus' bill) is ignored since we want to consider policies which are important enough that they can become salient in the election.
} 
policy becomes the status quo for the second period. If one party gets the majority of votes in the election, it implements its preferred policy. Otherwise, a coalition government is formed, in which case unanimity among governing parties is required for adopting a level of public spending different from $g_{1}$ and for implementing (repealing, resp.) the reform had it not been (had it been, resp.) passed in the first period.

\subsection{Citizens}

The polity $\mathcal{N}$ consists of a (odd) finite number of citizens $N$ who differ over their preferences for the two policies. With respect to the reform issue, there are two preference types, indexed by $j \in\{P, A\}$, where $P$ ( $A$, resp.) stands for pro-reform (anti-reform, resp.). Let $r_{j}$ denote the preferred reform outcome of a type- $j$ citizen, where $r_{j}=1(0$, resp.) if $j=P$ ( $A$, resp.). A citizen of reform type $j$ obtains a net benefit $\beta_{j}$ when the reform is in effect, with $\beta_{P}>0>\beta_{A}$. With respect to the public spending issue, each citizen has a unique ideal level $g^{\ell} \in[0,1]$ (though more than one citizen can have the same bliss point). A citizen of spending type $\ell$ obtains a utility $-\left\|g^{\ell}-g\right\|$ from a public spending level $g$, where $\left\|g^{\ell}-g\right\|$ is the distance between $g$ and $g^{\ell}{ }^{14}$ The utility a type- $(\ell, j)$ citizen obtains from the period- $t$ policy $p_{t}=\left(g_{t}, r_{t}\right)$, is then $u_{j}^{\ell}\left(g_{t}, r_{t}\right)=-\left\|g^{\ell}-g_{t}\right\|+\beta_{j} r_{t}$.

Let $N_{j}$ be the number of reform type- $j$ citizens in the polity and $F_{j}$ the (discrete) distribution of spending preference types among the reform type- $j$ citizens. $F_{j}(g)$ is thus the number of reform type- $j$ citizens whose preferred level of public spending lies at or below $g$. By definition, $N_{j}=F_{j}(1)$ and $N_{P}+N_{A}=N$. Also, let $F(g) \equiv$ $F_{P}(g)+F_{A}(g)$. I assume throughout that $N_{P}>N_{A}$, i.e. the number of anti-reform citizens is smaller than the number of pro-reform ones. Hence, implementing the reform is the outcome preferred by the majority.

\subsection{Parties}

Candidates are put forward by three political parties indexed by $i \in I=$ $\{L, M, R\}$, where $I$ is the set of parties and $L$ stands for leftist, $M$ for median and $R$ for rightist. Parties are treated as unitary actors. ${ }^{15}$ Each party is characterized by its stance on public spending - $g^{i} \in[0,1]$ - and on the reform issue $j^{i} \in\{P, A\}$. Assume $g^{L}<g^{M}<g^{R}$, and let $\mathcal{J} \equiv\left(j^{L}, j^{M}, j^{R}\right)$ denote the profile of parties' reform types.

When in office, a politician derives utility from both policies as well as from ego rents. When not in office, he receives utility only from the policies. In both cases, politicians discount future utility by a factor $\delta \in(0,1)$. The utility a reform type- $j$ politician $i$ derives from the period- $t$ policy $p_{t}=\left(g_{t}, r_{t}\right)$ is $u_{j}^{i}\left(g_{t}, r_{t}, m_{\# \mathcal{C}}\right)=$ $-\left\|g^{i}-g_{t}\right\|+\beta_{j} r_{t}+m_{\# \mathcal{C}}$, where $m_{\# \mathcal{C}}$ denotes the ego rent if the party is in office, with $\# \mathcal{C}$ the number of parties in government $\mathcal{C}$, and $m_{\# \mathcal{C}}=0$ if the party is not

\footnotetext{
${ }^{14}$ Two things should be noted. First, in order to avoid any confusion with the absolute value sign |.| I denote Euclidean preferences by $\|$.$\| . Second, it is worth remarking that the assumption$ of Euclidean preferences is not key to the argument. It only allows us to present the results in a clean and tractable way.

${ }^{15}$ Considering parties as unitary actors is motivated by the observation that they are traditionally well-disciplined in parliamentary democracies (for a discussion, see Laver and Shepsle (1994) or Laver and Schofield (1998)). Therefore, I will throughout speak equally of parties and politicians.
} 
in office. I assume $m_{1}>m_{2}>0$, i.e. the ego rent a party gets decreases with the number of parties in the government. ${ }^{16}$

The leftist and median parties are assumed to be in office in the first period while the rightist party is in the opposition.

\subsection{Information}

The distribution of types within the population (i.e. $F$ ) and the position of each party on the public spending issue (i.e. $g^{i}$ ) are public knowledge. ${ }^{17}$ However, there is asymmetric information in that, contrary to politicians, citizens observe neither the profile of parties' reform types, nor the policy decision of each coalition partner. This makes it difficult for them to determine who is responsible for deadlock when the reform is not adopted in the first period. But citizens can form an initial estimate of the likelihood that a party is of the pro-reform type (e.g. they might observe the roll call over related issues). ${ }^{18}$ Let $\theta^{i} \in(0,1)$ denote such an initial reputation for party $i$, with $\Theta \equiv\left(\theta^{L}, \theta^{M}, \theta^{R}\right)$. While parties' reform types are observed only by politicians, their initial reputations are common knowledge (e.g. through newspaper polls).

\subsection{Political Equilibrium}

The interaction described above defines a two-period game between citizens and political parties. The timing of the game is as follows: (1) parties' reform types are independently chosen by Nature, and observed solely by politicians; (2) the leftist and median parties choose the first-period policy $p_{1}=\left(g_{1}, r_{1}\right) ;(3)$ citizens observe $p_{1}$ and cast their ballot for one of the three parties; (4) a second-period government is formed; and (5) the newly elected government chooses the second-period policy $p_{2}=\left(g_{2}, r_{2}\right)$. We discuss these stages in reverse order.

Second-Period Policy Choice. Let $\mathcal{C}_{2} \subseteq I$ denote the second-period government. It has to choose the policy $p_{2}=\left(g_{2}, r_{2}\right)$, first deciding on the reform issue and then on public spending. For each issue, a governing party proposes a policy outcome. If all parties in the government propose the same outcome, it is implemented. Otherwise, the first-period policy remains in place. ${ }^{19}$ Hence, for each issue, a policy different from the status quo is implemented only if all the parties in office agree on it.

\footnotetext{
${ }^{16}$ Ego rents are exogenously given and equal for each party in office. However, this assumption is not restrictive. Indeed, the model can be extended to allow parties to bargain on how to allocate the spoils of office among the coalition partners. It can also accomodate ego rents which vary with each party's vote share (e.g. reflecting the fact that there is traditionally a relation between the number of cabinet portfolios a party gets and the proportion of its parliamentary seats among the coalition partners).

${ }^{17}$ The public knowledge nature of parties' stance on public spending would apply to issues with a strong ideological content or to issues which have been the object of a long-standing contention, thus leading to an extensive media coverage (reports, debates, ...). For example, citizens traditionally know that Democrats prefer spending more on welfare programs than Republicans.

${ }^{18}$ Note that prior beliefs can also be related to the proportion of pro- and anti-reform agents. This would follow a citizen-candidate approach where each party selects its candidates among the citizens who share its preferences for public spending. Priors would then reflect the probability that party $i$ picks a pro-reform partisan. Our results are consistent with this interpretation.

${ }^{19}$ This specification of the decision process is meant to capture the unanimity rule discussed above.
} 
Since the second period is the last one, parties have no incentive to make a policy proposal different from the one they prefer. Two cases are possible, depending on the type of government. First, suppose a single-party government has been formed. The ruling party $i$ will then implement its preferred policy, i.e. $p_{2}=\left(g^{i}, r^{i}\right)$. Suppose instead that a coalition government has been formed. Let $\mathcal{P}\left(\mathcal{C}_{2}, g_{1}\right) \equiv$ $\left\{g \in\left[g^{L}, g^{R}\right]:-\left\|g^{k}-g\right\| \geq-\left\|g^{k}-g_{1}\right\|\right.$ for all $\left.k \in \mathcal{C}_{2}\right\}$ be the set of public spending levels which are (weakly) preferred to $g_{1}$ by all coalition members. ${ }^{20}$ The unanimity requirement implies that the set of equilibrium outcomes is the (nonempty) subset of $\mathcal{P}\left(\mathcal{C}_{2}, g_{1}\right)$ containing all the levels of public spending which are Pareto optimal for the coalition members. With respect to the reform issue, the first-period decision will be reversed (i.e. $r_{2}=1$ when $r_{1}=0$ or $r_{2}=0$ when $r_{1}=1$ ) only if all coalition parties are of the same reform type (type $P$ for $r_{2}=1$ and type $A$ for $r_{2}=0$ ). Otherwise, $r_{2}=r_{1}$.

Government Formation. Let $v^{i}$ be the number of votes party $i$ receives in the election and $v \equiv\left(v^{L}, v^{M}, v^{R}\right)$ the vector of vote totals. Also denote by $\mathcal{W}_{\mathcal{C}} \equiv$ $\left\{\mathcal{C} \subseteq I: \sum_{k \in \mathcal{C}} v^{k} \geq \frac{N+1}{2}\right\}$ the set of possible governments, i.e. those whose vote total is majoritarian. ${ }^{21}$ If $v^{i} \geq \frac{N+1}{2}$ for some party $i$, then that party assumes office alone. If no party receives an overall majority, a coalition government has to be formed. There are several ways to model the coalition formation process. I adopt the fixed-order coalition formation procedure due to Austen-Smith and Banks (1988) where parties are selected as the formateur in a pre-specified order, the party with the largest vote share first, then the second largest if the first one fails, and so on (in the event of a tie between several parties, each of them is selected first with an equal probability). ${ }^{22}$ The formateur proposes a coalition and parties then decide whether to accept or reject the formateur's offer. If it is accepted, the second-period government is formed. If it is rejected, the party with the next largest vote share is then asked to form a coalition. And if none of the three parties manage to form a coalition, a caretaker government assumes office. The first-period policy then remains in place, and none of the parties receives an ego rent.

A strategy for party $i$ in the coalition formation stage thus consists of two elements: a proposal and a response strategies. First consider a party $i$ which is proposed to join coalition $\mathcal{C}$. If it accepts, it gets a second-period utility $u_{j}^{i}\left(p_{2}\left(p_{1}, \mathcal{C}\right), m_{\# \mathcal{C}}\right)$, where $\# \mathcal{C}$ is the number of parties in the coalition and $p_{2}\left(p_{1}, \mathcal{C}\right)$ its (correct) beliefs of the policy that government $\mathcal{C}$ will implement given the first-period policy $p_{1}$. If party $i$ rejects the offer, it correctly anticipates that a government $\overline{\mathcal{C}}$ will assume office, and that it will obtain a utility $u_{j}^{i}\left(p_{2}\left(p_{1}, \overline{\mathcal{C}}\right), m\right)$, where $m$ is the ego rent it gets when $\mathcal{C}_{2}=\overline{\mathcal{C}}$. Thus party $i$ agrees to join coalition $\mathcal{C}$ if and only if

\footnotetext{
${ }^{20}$ Note that $\mathcal{P}\left(\mathcal{C}_{2}, g_{1}\right)$ is non-empty since either $g_{1} \in \mathcal{P}\left(\mathcal{C}_{2}, g_{1}\right)$ if $g_{1} \in\left[g^{L}, g^{R}\right]$ or $g^{L} \in$ $\mathcal{P}\left(\mathcal{C}_{2}, g_{1}\right)\left(g^{R}\right.$, resp.) if $g_{1}<g^{L}\left(g_{1}>g^{R}\right.$, resp. $)$.

${ }^{21}$ This excludes the possibility of a minority government, i.e. one which controls less than half the parliamentary seats. This is motivated by the fact that we consider stable governments (see Laver and Schofield (1998) for evidence on the lower stability of minority governments).

${ }^{22}$ The other procedure commonly found in the literature on coalition formation is the probabilistic one due to Baron and Ferejohn (1989), where each party is appointed as the formateur with a probability proportional to its vote share (for an application of this procedure see for example Baron and Diermeier (2001)). There is a debate on which of those rules is empirically relevant. Indeed, while Austen-Smith and Banks (1988) claim that the fixed-order procedure is a widespread convention, Diermeier and Merlo (2004) find little empirical support for this rule while the probabilistic one fits the data well. This raises the question of how robust the results are. In fact, it can be shown that they would also hold under the probabilistic rule (with an extra requirement on incumbents' vote shares in proposition 4).
} 
$u_{j}^{i}\left(p_{2}\left(p_{1}, \mathcal{C}\right), m_{\# \mathcal{C}}\right) \geq u_{j}^{i}\left(p_{2}\left(p_{1}, \overline{\mathcal{C}}\right), m\right)$.

Now consider a formateur party $i$. It always proposes a coalition $\mathcal{C}$ such that $i \in$ $\mathcal{C}$. Moreover, since ego rents decrease with the number of parties in the government and that each party has veto power, it never proposes a consensus government (i.e. a government that includes all three parties). Now, if party $i$ proposes a coalition with party $k$, it gets an expected utility

$$
U_{j}^{i}\left(p_{1}, \mathcal{C}, \mathcal{J}\right)=\pi^{k} u_{j}^{i}\left(p_{2}\left(p_{1}, \mathcal{C}\right), m_{2}\right)+\left(1-\pi^{k}\right) u_{j}^{i}\left(p_{2}\left(p_{1}, \overline{\mathcal{C}}\right), m\right)
$$

, where $\pi^{k}$ is the probability that party $k$ accepts party $i$ 's offer and $\overline{\mathcal{C}}$ the government which will form following a rejection.

Hence, party $i$ proposes party $k$ that solves

$$
\max _{k \neq i}\left\{U_{j}^{i}\left(p_{1},\{i, k\}, \mathcal{J}\right) \mid\{i, k\} \in \mathcal{W}_{\mathcal{C}}\right\}
$$

In the event party $i$ is indifferent between forming a coalition with any of the other two parties, I assume it proposes each with an equal probability.

Election. At the end of the first period, there is an election held under a pure proportional representation electoral system. Citizens make their voting decision strategically, anticipating which governments may form and the policies which may then be enacted in the second period. ${ }^{23}$ The problem is that citizens do not observe parties' reform types, and therefore cannot predict which policy each party will want to implement and who will take office if a coalition has to be formed. However, from the first-period policy outcome $p_{1}=\left(g_{1}, r_{1}\right)$ and parties' initial reputations $\Theta$, citizens can form beliefs about the profile of parties' reform types $\mathcal{J}$. Let $\mu^{i}\left(\Theta, p_{1}\right)$ denote citizens' posterior beliefs that party $i$ is pro-reform. They are derived from the priors and incumbents' first-period strategies through Bayes' rule whenever possible and are therefore the same for all citizens in equilibrium.

The voting strategy of a type- $(\ell, j)$ citizen is a function $\alpha_{j}^{\ell}$ which, given her beliefs on parties' reform types, prescribes for each party $i$ a probability $\alpha_{j}^{\ell}\left(i \mid \Theta, F, p_{1}\right)$ that she votes for party $i$, with $\sum_{i \in I} \alpha_{j}^{\ell}\left(i \mid \Theta, F, p_{1}\right)=1$. Denote by $\alpha$ the profile of voting decisions, and let $E U_{j}^{\ell}\left(\Theta, p_{1}, \alpha\right)$ be the second-period utility a type- $(\ell, j)$ citizen expects given the profile of voting decisions $\alpha$ and her beliefs about the second-period policy outcome.

We can now define a voting equilibrium.

Definition 1. (Voting equilibrium) Given parties' initial reputations $\Theta$, the distribution of types within the population $F$ and the first-period policy outcome $p_{1}=\left(g_{1}, r_{1}\right)$, a strategy profile $\alpha^{*}\left(\Theta, F, p_{1}\right)$ is an equilibrium of the voting stage if and only if for all $S \subseteq \mathcal{N}$ and for all $\alpha^{S}$, there exists a citizen in $S$ such that $E U_{j}^{\ell}\left(\Theta, p_{1}, \alpha^{*}\right) \geq E U_{j}^{\ell}\left(\Theta, p_{1}, \alpha^{S}, \alpha^{-S *}\right)$.

This definition requires the voting equilibrium to be a Strong Nash Equilibrium. This refinement of the Nash Equilibrium concept imposes stability against deviations not only by individual voters but also by every possible group of voters. The rationale for imposing such a strong refinement is twofold. First, Nash Equilibrium is too weak a concept. Indeed, whenever a citizen is not pivotal, the outcome of the

\footnotetext{
${ }^{23}$ For evidence of strategic voting in elections under proportional representation, see Cox (1997).
} 
election will be independent of her voting decision, and therefore any strategy will be a best response to the voting strategies of the other citizens. Second, it allows us to show that even if citizens can coalesce when making their voting decision, there still exist equilibria where politicians play the blame-game.

First-Period Policy Choice. The leftist and median parties are in office. They have to choose the first-period policy $p_{1}=\left(g_{1}, r_{1}\right)$. While the decision process is the same as in the second period, the policy choice may be different for three reasons. One is the status quo policy. Denote by $p_{0}=\left(g_{0}, r_{0}\right)$ the policy in place at the beginning of the first period, and assume that the reform is not in effect (i.e. $r_{0}=0$ ). Also consider for simplicity the case where $g_{0}=g^{M}$, i.e. the status quo level of public spending is the one preferred by the median party. ${ }^{24}$ The second is that parties have reputational concerns. Indeed, voters use the first-period policy outcome in order to draw some inferences about the reform types of the incumbents. Hence, coalition members improve their reputation as supporters of the reform by implementing it in the first period. Citizens also realize that the reform type of the rightist party may influence incumbents' first-period policy decisions, and thus use this information to update their beliefs about the reform type of the rightist party. The third difference is that the policy adopted in the first period becomes the status quo for the second period. And this status quo may determine who will assume office in the second period in the event a coalition government has to be formed. Incumbents take this into account when making their policy decision.

An incumbent $i$ 's first-period strategy is a pair $\left(\sigma_{1}^{i}, \gamma_{1}^{i}\right)$ which consists of reform and public spending strategies. The reform strategy is a function $\sigma_{1}^{i}$, where $\sigma_{1}^{i}\left(\Theta, \mathcal{J}, F, p_{0}\right)$ is the probability that incumbent $i$ adopts the reform. This depends on the status quo policy $p_{0}$, on the level of public spending he expects to be implemented after the reform choice, on his anticipation of citizens' voting decisions (which depend on parties' initial reputations $\Theta$, the distribution of types within the population $F$ and the first-period policy outcome $p_{1}$ ) and of the government which will form and the policy implemented in the second period (which depend on the first-period policy outcome, the election outcome and the profile of parties' reform types $\mathcal{J}$ ). Similarly, a public spending strategy for incumbent $i$ is a function $\gamma_{1}^{i}$, where $\gamma_{1}^{i}\left(\Theta, \mathcal{J}, F, p_{0}, r_{1}\right)$ is party $i$ 's proposed level of public spending which also depends on the first-period reform decision $r_{1} \cdot{ }^{25}$ Denote by $V_{j}^{i}\left(p_{1}\right)$ the second-period expected utility of a reform type- $j$ party $i$ when the first-period policy is $p_{1}$. An incumbent $i$ chooses his first-period strategy to maximize his expected

\footnotetext{
${ }^{24}$ This assumption is made to simplify the analysis. An incumbent's incentives to play the blamegame are different for a different $g_{0}$. For some values, an incumbent might rely upon the public spending issue to prevent its coalition partner from playing the blame-game. For other values, it might provide an incumbent with the incentive to play the blame-game, incentive he would not have had otherwise. However, presenting the results for each $g_{0}$ would not only be tedious but would also significantly complicate the analysis without adding much to our understanding of the argument, the basic intuition remaining unchanged. It seems therefore reasonable to consider a specific level of the status quo. Now letting $g_{0}=g^{M}$ is a natural choice given that $g^{M}$ corresponds to what can be interpreted as the long-run or stable level of public spending (for a discussion of this point, see Austen-Smith (2000) whose argument, although developed in a slightly different framework, applies to the present model. See also Baron (1996)).

${ }^{25}$ In order to simplify the notation, I will throughout omit $\Theta, F$ and $p_{0}$ from the arguments of $\sigma_{1}^{i}$ and $\gamma_{1}^{i}$.
} 
intertemporal payoff, i.e.

$$
\left\{\begin{array}{l}
\sigma_{1}^{i}(\mathcal{J}) \in \underset{\sigma_{1}^{i} \in[0,1]}{\arg \max }\left\{u_{j}^{i}\left(p_{1}\left(\sigma_{1}\right), m_{2}\right)+\delta V_{j}^{i}\left(p_{1}\left(\sigma_{1}\right)\right)\right\}, \text { and } \\
\gamma_{1}^{i}\left(\mathcal{J}, r_{1}\right) \in \underset{\gamma_{1}^{i} \in[0,1]}{\arg \max }\left\{u_{j}^{i}\left(g_{1}\left(\gamma_{1}\right), r_{1}, m_{2}\right)+\delta V_{j}^{i}\left(g_{1}\left(\gamma_{1}\right), r_{1}\right)\right\}
\end{array}\right.
$$

, where $\sigma_{1}=\left(\sigma_{1}^{L}, \sigma_{1}^{M}\right)$ and $\gamma_{1}=\left(\gamma_{1}^{L}, \gamma_{1}^{M}\right)$.

Finally, note that each party deciding with probability one not to implement the reform in the first period or to keep the status quo level of public spending is always an equilibrium. To see this, recall that both parties must agree to the reform or to a level of public spending different from $g_{0}$. Hence, if the other coalition member does not adopt the reform or proposes $g_{0}$, acting differently does not change the policy outcome. As a result, neither party has an incentive to deviate. However, there are situations where both incumbents would be better off implementing the reform or a level of public spending different from the status quo. In those cases, such equilibria require a coordination failure. But this does not seem realistic in this game. I thus disregard those coordination failures by assuming that incumbents' strategies are weakly undominated (i.e. incumbents choose their first-period strategy conditional on being pivotal).

Political Equilibrium. A Perfect Bayesian Equilibrium of this game consists of: (i) first-period policy choice strategies for both the leftist and median parties; (ii) a voting strategy for each citizen; (iii) government formation strategies for each party; ( $i v)$ second-period policy choice strategies for each party; and $(v)$ voters' beliefs concerning the reform type of each party. ${ }^{26}$ These must satisfy the following requirements. First, strategies for the leftist and median parties (government formation as well as first- and second-period policy choice strategies) must be optimal given other parties' strategies and citizens' strategies and beliefs. Second, strategies for the rightist party (government formation and second-period policy choice strategies) must be optimal given other parties' strategies. Third, citizens' posterior beliefs are derived from incumbents' strategies through Bayes' rule where possible. Finally, a citizen's strategy (a voting rule) must be optimal given her beliefs and parties' strategies.

\section{BLAME-GAME POLITICAL EQUILIBRIA}

We now investigate the existence of blame-game political equilibria. A proreform party is said to play the blame-game if it vetoes the adoption of the reform and takes advantage of the voters' inability to determine where responsibility for the policy outcome lies. A blame-game equilibrium is then defined as an equilibrium in which some parties play the blame-game. It is worth noting that this may happen only in the first period. Indeed, the second period being the last one, parties have at that time no reputational concerns and thus no incentive to propose a reform outcome different from the one they prefer.

Throughout the analysis, I will maintain the following technical assumption:

Assumption $1(i)\left|\beta_{A}\right| \geq \frac{\delta}{1-\delta}\left(m_{1}+g^{M}-g^{L}\right)$; and $(i i) \theta^{R} \in\left(\frac{g^{R}-g^{L}}{\beta_{P}}, 1-\frac{g^{R}-g^{M}}{\beta_{P}}\right)$.

\footnotetext{
${ }^{26}$ Note that the equilibrium concept used here is actually stronger than Perfect Bayesian Equilibrium since the voting equilibrium has to be a Strong Nash Equilibrium.
} 
Part (i) guarantees that an anti-reform party will never want to implement the reform. This assumption is made to be consistent with the idea that an incumbent plays the blame-game in order to damage the reputation of its coalition partner by letting the voters believe that the latter is of the anti-reform type and thus is the one who vetoed the adoption of the reform. ${ }^{27}$ Part (ii) puts lower and upper bounds on the initial reputation of the rightist party. Note that while being sufficient for the characterization of blame-game political equilibria, assumption 1 is in most cases much stronger than necessary.

The analysis that follows will focus on political equilibria where the first-period policy outcome is always $p_{1}=\left(g^{M}, 0\right)$, i.e. the reform is not implemented and the level of public spending is the one preferred by the median party. This means that citizens obtain no information from the first-period policy outcome and therefore that Bayes' rule implies $\mu^{i}\left(\Theta, g^{M}, 0\right)=\theta^{i}$ for all $i \in I$, i.e. citizens' posterior beliefs on parties' reform types coincide with their priors. However, the definition of a Perfect Bayesian Equilibrium does not put any restriction on beliefs off the equilibrium path. For simplicity, I adopt the following ones: $\mu(\Theta, g, 1)=\left(1,1, \theta^{R}\right)$ for all $g$ and $\mu(\Theta, g, 0)=\left(0,0, \theta^{R}\right)$ for $g \neq g^{M}$, where the first entry (second and third, resp.) corresponds to the posterior beliefs that the leftist party (median and rightist, resp.) is pro-reform. ${ }^{28}$ It is worth emphasizing that those are not the only beliefs that support the equilibrium outcomes presented below. Moreover, they satisfy Cho and Kreps' (1987) Intuitive Criterion. ${ }^{29}$

The following sub-sections identify each a different motivation for a politician to play the blame-game.

\subsection{Issue salience in the electoral debate}

The first two propositions show an incumbent who is willing to play the blamegame in order to keep the reform issue salient in the electoral debate.

\footnotetext{
${ }^{27}$ There is another reason for considering only equilibria where an anti-reform politician always vetoes the adoption of the reform. Situations where an agent has preferences opposed to those of a principal and yet decides to conform in order to enhance his reputation, have already been studied (see for example Barro (1973), Ferejohn (1986) or Austen-Smith and Banks (1989) for agency style models of political competition where elections give politicians the incentive to make decisions in accordance with the desires of their constituents). Instead I will focus on situations where the principal (viz. the majority of voters) and the agent (viz. incumbents) have the same preferences but the agent nevertheless decides not to adopt the policy they both desire.

${ }^{28}$ Note that if the incumbents anticipate that a coalition government will have to be formed in the second period, they might want to implement a level of public spending different from $g^{M}$. Suppose for instance that the rightist party will be the first to be appointed as the formateur and that it is indifferent between forming a coalition government with any of the other parties. It will then propose each of them with an equal probability. Anticipating that both will accept the offer, incumbents may then agree on $g_{1}=\left(g^{M}+\varepsilon\right)$ for $\varepsilon>0$ arbitrarily small. They will now have an incentive to reject the rightist party's offer and wait for one of them to be appointed as the formateur. This incentive comes from the fact that the rightist party will veto any $g_{2}<g_{1}$ while by renewing the coalition, incumbents will be able to implement a level of public spending they both prefer, e.g. $g_{2}=g^{M}$. Hence, by losing $\varepsilon$ in the first period, they increase their probability of staying in office from one half to one. $\mu(\Theta, g, 0)=\left(0,0, \theta^{R}\right)$ for $g \neq g^{M}$ allows us to rule out this possibility and therefore to concentrate on blame-game strategies, the focus of the paper.

${ }^{29}$ Since an anti-reform party always vetoes the adoption of the reform (by assumption $1(i)$ ) and because of the unanimity rule, the reform is implemented only if both incumbents are of the proreform type. Thus $\mu(\Theta, g, 1)$. In the same time, equilibrium dominance does not eliminate any reform type following a first-period policy outcome $p_{1}=(g, 0), g \neq g^{M}$, given that they might all prefer to propose a level of public spending $g \neq g^{M}$ if they would then get the absolute majority in the next election.
} 
Let $\widetilde{\theta} \equiv \theta^{L} \theta^{M}+\theta^{R}\left[\theta^{L}\left(1-\theta^{M}\right)+\left(1-\theta^{L}\right) \theta^{M}\right]$ be the initial beliefs that at least two parties are pro-reform. We have the following result.

Proposition 1. Suppose assumption 1 is satisfied. There exist $\bar{\theta} \in(0,1)$ and distributions of preference types within the population $(F)$ such that there is a political equilibrium in which a pro-reform leftist incumbent always vetoes the adoption of the reform in the first period in order to get the votes of all pro-reform citizens if his initial reputation exceeds $\bar{\theta}$ and the following two conditions hold: (i) $\max \left\{\theta^{M}, \theta^{R}, \tilde{\theta}\right\}<\frac{\beta_{P}-\left(g^{R}-g^{L}\right)}{\beta_{P}}$; and (ii) $\delta\left(m_{1}-m_{2}\right) \geq \beta_{P}+\left(g^{M}-g^{L}\right)$.

The proof of this and all subsequent results are reported in the Appendix. ${ }^{30}$

Condition $(i)$ puts an upper-bound on the priors, thus ensuring $\bar{\theta}<1 .{ }^{31}$ Condition (ii) says that a pro-reform incumbent is more office than policy motivated in the sense that the present value of the utility gain from getting the absolute majority tomorrow exceeds the gain from having his preferred policy implemented in the first period.

The intuition underlying this result runs as follows. Consider a first-period coalition where both incumbents are pro-reform. ${ }^{32}$ Also suppose without loss of generality that the median party proposes to adopt the reform, and thus that party $L$ 's first-period reform decision is pivotal. A pro-reform leftist party knows that if the reform is implemented in the first period, citizens will infer that both incumbents are of type $\mathrm{P}$. This comes from the fact that an anti-reform politician prefers the status quo and that both incumbents must agree for the reform to pass. Now, if the leftist party anticipates it will not get the absolute majority, it may decide to veto the adoption of the reform. And given that incumbents have no electoral advantage to agree on a level of public spending different from $g^{M}$, we have $p_{1}=\left(g^{M}, 0\right)$ for any profile of incumbents' reform-preference types, and citizens do not get any information on parties' reform types. In other words, while voters observe that the reform is not enacted, they are not sure whether it comes from a type-P party L playing the blame-game or from an anti-reform incumbent who implements his preferred reform outcome. Because of his high initial reputation as supporter of the reform $\left(\theta^{L}>\bar{\theta}\right)$, the leftist incumbent will then get all the pro-reform votes and thus the absolute majority. ${ }^{33}$ Hence, proposition 1 shows a pro-reform politician who plays the blame-game in order to gain the absolute majority in the next election by taking advantage of his reputation on that issue.

This result is consistent with the observation that coalition governments tend to respond slowly to unexpected fiscal deficits. But contrary to the previous literature, it does not require heterogeneous policy preferences among coalition members in order to explain this observation. To illustrate this, consider a coalition government made up of a left-wing and a right-wing party. During their term in office, a shock arises that requires the adoption of a stabilization program. Both parties as well as a majority of the electorate are in favor of such a program. Parties know that if it is implemented neither of them will get the majority in the next election. Hence, the

\footnotetext{
${ }^{30}$ The conditions on the distribution of preference types $(F)$ are formally stated there as well.

${ }^{31}$ Note that $\frac{\beta_{P}-\left(g^{R}-g^{L}\right)}{\beta_{P}}>0$ follows from $1>\theta^{R}>\frac{g^{R}-g^{L}}{\beta_{P}}$ (by assumption $\left.1(i i)\right)$.

${ }^{32} \mathrm{It}$ is worth mentioning that although we discuss only the case of a pro-reform coalition (since the focus of the paper is on a pro-reform party playing the blame-game), all the results and proofs are established for any profile of parties' reform types.

${ }^{33}$ One may wonder how restrictive $\theta^{L}>\bar{\theta}$ is. To give just an example, suppose $g^{L}=1 / 3$, $g^{R}=2 / 3, \beta_{P}=4 / 3, \theta^{M}=1 / 2$ and $\theta^{R}=1 / 4$. Then this condition requires $\theta^{L}>3 / 4$.
} 
right-wing members of the cabinet may decide to block the adoption of this fiscal stabilization program, taking advantage of their reputation as being fiscally tough, and blame the left-wing party for the deadlock. Pro-reform citizens will then bias their vote towards the right-wing party since it appears to be more likely than the leftist to implement the program.

Playing the blame-game can be interpreted here as a way to make the reform the campaign issue of the next election. Indeed, if the reform is implemented in the first period, citizens will infer that both coalition parties are pro-reform. The salient issue for the swing voter then shifts from the reform to public spending. The problem is that the leftist party has no particular advantage on this latter issue. Instead, if party L plays the blame-game, the question of which parties are of type $\mathrm{P}$ remains, and with it the focus of the election campaign on the reform issue. And here the leftist party can benefit from its reputational advantage. By his policy choice, an incumbent can thus focus the election campaign on some specific issues, thereby eliminating candidates who can prevent him from winning the election.

This provides a possible explanation for the strategy followed by Jacques Chirac during the 2002 Presidential election campaign in France, where he blamed Jospin for the non-adoption of homeland security reforms. ${ }^{34}$ Chirac, having a better reputation as a supporter of a tight security policy than Jospin, may have strategically chosen to delay the adoption of those reforms knowing that Jospin was weaker on that issue and thus could be defeated if this issue becomes salient in the presidential election.

In the above proposition, a politician plays the blame-game in order to get the absolute majority in the next election. And he does so by taking advantage of his reputation as a supporter of the reform. The next result shows that a politician may also play the blame-game in order not to attract votes but to split another candidate's electorate by taking advantage of that candidate's reputation being relatively low and not necessarily of his own being high.

Proposition 2. Suppose assumption 1 is satisfied. There exist $\bar{\theta} \in[0, \widetilde{\theta})$ and distributions of preference types within the population $(F)$ such that there is a political equilibrium in which a pro-reform leftist incumbent always vetoes the adoption of the reform in the first period in order to deprive his coalition partner from getting the majority of votes in the next election if the initial reputations of the leftist and rightist parties exceed $\bar{\theta}$ and the following two conditions hold: $(i)\left(\theta^{i}-\widetilde{\theta}\right)<\frac{\left|g^{i}-g^{M}\right|}{\beta_{P}}$ for all $i \in I$; and $\left(\right.$ ii) $\delta \frac{m_{2}}{2} \geq \beta_{P}+\left(g^{M}-g^{L}\right)$.

As in proposition 1, condition $(i)$ puts an upper-bound on the initial reputations. Condition (ii) says that for a pro-reform incumbent the present value of the expected utility gain from being in office tomorrow exceeds the utility gain from having his preferred policy implemented today.

The logic underlying this result runs as follows. Consider again a pro-reform coalition where the median party proposes to adopt the reform. If the reform is implemented in the first period, citizens will infer that both incumbents are of type $\mathrm{P}$ and, given its stance on the public spending issue, the median party will get a majority of votes. The leftist party may then choose to veto the adoption of the

\footnotetext{
${ }^{34}$ It is worth remarking that French Presidential elections are held under plurality runoff, not proportional representation. However, the argument developed here can be extended to this electoral system.
} 
reform, thereby depriving the voters from the assurance that party $\mathrm{M}$ is of the proreform type. But if the reform issue is salient for some of the pro-reform citizens who would have voted for the median party had the reform been implemented and the reputation of this party is relatively low (i.e. $\theta^{M}<\widetilde{\theta}$, which follows from condition $(i)$ ), those citizens will prefer to cast their ballot for another party. Hence they swing the election by depriving the median party from the absolute majority. In other words, by playing the blame-game, the leftist incumbent makes the reform the salient issue in the election. Now if neither party gets the absolute majority in the election, a coalition has to be formed. Since the median incumbent had no electoral advantage to agree on a level of public spending different from his preferred one, $g_{1}=g^{M}$ and therefore any coalition government will implement $g_{2}=g^{M}$ as well. Suppose now that the rightist party is of the anti-reform type. Since it would have the power to veto the adoption of the reform in the second period (and it would definitely use that power), the incumbents are better off renewing the first-period coalition (eventually rejecting an offer to join the rightist party in a coalition in the event this party is the first to be appointed as the formateur). Instead, if the rightist party is also of the pro-reform type, then any coalition will implement the reform, and the second-period government will consist of the party which is first appointed as the formateur and each of the other two parties with an equal probability. To sum up, party L plays here the blame-game in order to prevent its coalition partner from getting the absolute majority in the next election, thereby making possible its participation in a second-period coalition. It does so by keeping the reform issue salient in the electoral debate thus taking advantage of its coalition partner having a relatively low reputation as a supporter of the reform.

To appreciate this argument, consider a coalition government composed of the Democratic and Green parties. The government has to decide whether to ban night flights at an airport. The Democratic party appears less likely to support this ban since some of its partisans are employed at the airport. But night flights are disturbing for the neighborhood and the environment, thus making the ban appealing for the Green party and the issue salient for people living close to the airport. Hence, those citizens will vote for parties which are likely to support the ban. Despite its preferences and the fact that the Democrats want to adopt the ban, the Green party may decide to reject it, and shift the responsibility onto the Democratic party.

This result contrasts with the previous one in two ways. First, the leftist party plays the blame-game in order to prevent its coalition partner from getting the absolute majority and not, as in proposition 1, to guarantee itself the majority. Second, the leftist party no longer relies solely on its reputation. It may even be the one among the three parties which is perceived by the voters as the least likely to support the adoption of the reform. In that case, it will have to rely on a higher reputation of the opposition party for splitting the electorate of its coalition partner. One example of this would be a left-wing party blocking immigration reforms and blaming its right-wing coalition partner for it. Its objective would be to weaken the electoral position of its coalition partner by inducing some of the latter's supporters to switch their vote to an extreme rightist party.

\subsection{Divided electorate}

The second motivation applies when an incumbent tries to hide his preference for the reform in order to avoid a split in his electorate that would cost him his 
anti-reform votes.

Proposition 3. Suppose assumption 1 is satisfied. There exist distributions of preference types within the population $(F)$ as well as $\underline{\theta}$ and $\bar{\theta}$ (with $0 \leq \underline{\theta}<\bar{\theta} \leq 1$ ) such that there is a political equilibrium where a pro-reform leftist party whose initial reputation lies between $\underline{\theta}$ and $\bar{\theta}$ always vetoes the adoption of the reform in the first period in order to hide its stance on the reform, provided the following two conditions hold: $(i) \frac{\max \left\{\theta^{M}, \theta^{R}, \widetilde{\theta}\right\}-\min \left\{\theta^{M}, \theta^{R}, \widetilde{\theta}\right\}}{2}<\frac{g^{M}-g^{L}}{\left|\beta_{A}\right|}$; and $(i i) \delta\left(m_{1}-m_{2}\right) \geq$ $\beta_{P}+\left(g^{M}-g^{L}\right)$.

This proposition tells us that an incumbent may play the blame-game because of the heterogeneity in his electorate's attitude towards the reform. ${ }^{35}$ To see this, suppose that the leftist electorate is majoritarian with a large fraction being of the anti-reform type. If the reform is implemented in the first period, citizens will infer that both incumbents are of type P. Anti-reform voters may then prefer casting their ballot for the opposition party if its initial reputation is low enough. This will deprive party L from the absolute majority it would have gotten had it obtained the votes of all the leftist citizens (pro- and anti-reform ones). Party L may then decide to veto the adoption of the reform. The first-period decision will thus convey no information about the reform types of the different parties and party L's reputation will now be closer to or lower than the opposition party's. This will then strip the leftist anti-reform citizens from the incentive they had to vote for party R. If in the same time party L's initial reputation is not too low such that the leftist pro-reform citizens have no incentive to vote for another party, party $\mathrm{L}$ will then obtain the leftist votes and thus the majority. By his policy choice, an incumbent can thus hide his stance on a specific issue and avoid a split in his electorate.

To illustrate this proposition, consider a coalition government consisting of the Democratic and Republican parties. This government has to decide whether to sign an environmental treaty. Opinions are divided. If the treaty is signed, the Conservatives will lose the support of a large fraction of their electorate who opposes it. Hence, the Conservative party may block the adoption of the treaty in order to satisfy its anti-reform members while at the same time letting its pro-reform members believe that the veto came from the Democratic party.

\subsection{Bargaining power in the coalition formation}

The last motivation applies to an incumbent who tries to enhance his bargaining power in the coalition formation process through one of the following channels. The first one is by increasing his vote share relative to the other parties in such a way that he is the first to be appointed as the formateur. The second one is by making the reform the salient issue in the coalition bargaining in order to take advantage of his stance on that issue.

Proposition 4. Suppose assumption 1 is satisfied. There exist $\bar{\theta} \in[0, \tilde{\theta})$ and distributions of preference types within the population $(F)$ such that there is a political equilibrium in which a pro-reform incumbent vetoes the adoption of the reform

\footnotetext{
${ }^{35}$ Note that condition $(i)$ puts here an upper-bound on how large the range of initial reputations can be, while condition (ii) just repeats condition (ii) from proposition 1.
} 
in the first period in order to guarantee his participation in the second-period coalition government by enhancing his bargaining power, if the initial reputations of the leftist and rightist parties exceed $\bar{\theta}$ and the same two conditions as in proposition 2 hold.

To understand the intuition behind proposition 4, consider as before a proreform coalition. But suppose now that neither party gets a majority of votes when the reform is implemented in the first period. Moreover assume for instance that the rightist party gets the largest vote total among the three parties. It will then be appointed as the formateur and propose a coalition with one of the incumbents, say the median party. Anticipating that his coalition partner will accept this offer, the leftist incumbent may decide to veto the adoption of the reform in the first period in order to prevent this from happening. Now two cases are possible.

First, suppose the rightist party is of the pro-reform type. The leftist incumbent will have an incentive to veto the adoption of the reform if by doing so it gets the largest vote share, thus being the first one to be asked to form the second-period government. Hence, an incumbent plays here the blame-game in order to increase his bargaining power in the coalition formation by being the one who is appointed first as the formateur.

Consider now the case where the rightist party is of the anti-reform type. The key to the argument here is that the reform issue will not be salient in the coalition formation bargaining if it is implemented in the first period. Indeed, any coalition government will keep the reform in place in the second period since at least one of the incumbents will be in office and will thus be able to veto a repeal of the reform. Instead if the reform is not adopted in the first period, it will be the salient issue in the coalition bargaining since only a pro-reform coalition will implement it in the second period. This will provide the leftist party with an incentive to play the blame-game. Indeed, if the median party accepts party R's offer, it knows that the latter will veto the adoption of the reform in the second period. The median party will thus prefer to reject the offer and instead share office with the pro-reform leftist party. Hence, as in propositions 1 and 2 this result shows an incumbent who plays the blame-game in order to keep an issue salient. But the target differs. Before it was aimed at the citizens whose change in their voting behavior was either giving the blame-game player the absolute majority in the election or depriving another party of the majority. Here it is directed towards the politicians whose change in their coalition formation behavior guarantees the blame-game player a seat in the second-period government.

\section{DISCUSSION}

There is no real puzzle to the non-adoption of a reform by a minority whose interests differ from the remaining of the population and who would be hurt by its implementation. Decision-makers then act in their best interest. In the present model this happens when at least one of the governing parties is of the anti-reform type. What is more surprising is when the reform is rejected by a majority who would have been better off carrying it out. This occurs when the veto comes from a member of a pro-reform coalition. But then, in any of the above results, the reform is implemented in the second period. Hence, the model provides an explanation for

why the adoption of a (welfare-enhancing) reform preferred by all the members of a 
coalition government as well as a majority of the electorate is sometimes delayed. ${ }^{36}$

While this model analyzes the case of a coalition government, its logic can be applied to many political systems where the government is divided. The French cohabitation between 1986 and 1988, where the executive was divided between a socialist president and a conservative cabinet, is a good illustration. During the 1988 presidential election campaign, incumbent President Mitterand and Prime Minister Chirac (the two major candidates in that election) blamed each other for having blocked the adoption of some reforms. The 1997-2002 cohabitation between President Chirac (Conservative) and Prime Minister Jospin (Socialist) is another good example. As I previously mentioned, during the 2002 presidential election campaign, Chirac who was running against Jospin blamed him for a lax attitude towards security, thus exploiting his better reputation as a supporter of a stringent security policy.

The model can also be applied to more general situations where several agents, having some private information, choose an action while the principal observes only the aggregate outcome. Consider first the example of a negotiation between a trade union and the management of a firm. An agreement satisfying both parties may be rejected by one of them in order to spoil the reputation of the other and obtain public support. The argument also applies to sports teams. Consider a football team that has just appointed a new coach who is disliked by the players. Some of them may then decide to play badly and blame this new coach for the team's poor results, hoping he will be laid off. Finally, consider a firm that has just hired a new manager. Then some of the incumbent managers, fearing that he will get the promotion they were expecting, may sabotage several projects and put the blame on him. What these examples all have in common is the principal's inability of determining where the responsibility for the currently bad results lies.

Finally, this model also shows that having a small party advocating a specific issue (the Green party, for instance) does not necessarily help their cause. Indeed, those parties often have a small electorate and therefore no hope of getting the absolute majority. In addition, citizens perceive them as the most likely to support the issue they champion. Thus, proposition 2 shows that if their policy motivation is not too strong, those small governing parties may have an incentive to block reforms they favor in order to prevent other parties from getting the absolute majority, which may thus allow them to stay in office. And proposition 4 demonstrates that they may also want to keep salient the issue they champion, thus preserving in the coalition formation process the advantage they derive from their policy stance. In fact, this argument holds even if they are not in the government. Indeed, some of the major governing parties may use the policy concerns of those small parties as a 'battlefield' during the election campaign - as Chirac may have done with the security policy, an issue championed by Le Pen's National Front party. ${ }^{37}$

\footnotetext{
${ }^{36}$ It is worth noting that in this model only delayed adoption can occur if all coalition members are pro-reform. However failure to implement such reforms can happen if some cabinet members are anti-reform.

${ }^{37}$ We can illustrate this argument using the example of social security reforms. The aging of the population in Western democracies requires an adjustment of social security programs. In some countries an elderly-people party has been formed. One might think that this will increase pressure on governing parties to adopt a reform. Our results suggest, however, that it is not necessarily the case. Let's first consider a situation where the elderly-people party is not in office. If the government is divided between two parties, say the Democratic and Republican parties, the former may want to veto such a reform. By doing so, it will strengthen the electorate's awareness of the necessity for such a reform and thereby weaken the Republican party which
} 


\section{CONCLUSION}

Most of the models that try to explain delays in the adoption of reforms do so in the context of a single-party government. In this paper I propose a model where the government is a coalition. The model takes into account two features of coalition governments, namely that decisions have to be unanimous and that cabinet members are collectively responsible for the decisions made. The paper then shows that those features create a rationale for delaying the adoption of a reform - that I call blame-game -, namely damaging the reputation of coalition partners (including his own) in order to improve one's electoral prospects relative to others'. The model shows that this can happen in a stable coalition government where all its members favor the reform, the citizens are rational and cooperate when making their voting decisions, and a majority of the electorate wants the reform to be passed.

The paper then goes on identifying three motivations for a coalition member to play such a game. A first motivation is to keep an issue salient in the next election. And this motivation may arise even if the coalition member is electorally at a disadvantage on that issue, provided that it is going to hurt others as well. A second motivation is to hide one's stance on an issue in order to prevent a split in one's electorate during the next election. A third motivation is to improve one's bargaining power in the formation of the next coalition government.

Hence the model predicts that we can expect delays in the adoption of a reform if one coalition member is sufficiently office-motivated and: (1) has either a high reputation on that issue, or an intermediate one with an electorate which is divided on that issue; (2) has a coalition partner with a relatively low reputation on this reform issue but an electoral advantage on another; or (3) who faces the risk of not being invited to join the next coalition government.

Finally the paper argues that having a small single-issue party may hurt the cause they champion. Indeed that or another party may want to play the blamegame in order to keep this issue salient in the next election, or in the formation of the next coalition government.

\section{REFERENCES}

[1] Aghion, Ph. and P. Bolton, 1990. Government domestic debt and the risk of default: a political-economic model of the strategic role of debt. In: Public Debt Management: Theory and History, Dornbusch, R. and M. Draghi (eds), Cambridge University Press, Cambridge, 315-345.

[2] Alesina, A. and A. Drazen, 1991. Why are stabilizations delayed?. American Economic Review 81, 1170-1188.

traditionally exhibits less interest in those welfare programs. The electoral race will then shift from Democratic vs. Republican to Democratic vs. elderly-people party. But the latter party, not having a well-defined program on other issues, will be defeated by the Democrats who will win the majority. Let's now consider the case where the elderly-people party is in office. If the government is divided between the Democratic party and the elderly-people party, the latter may want to play the blame-game. By doing so, it may prevent the Democratic party from getting the majority and thus may guarantee itself a participation in the next cabinet. Or, it may leave to the next government the decision to reform the social security system. Now if the Democrats want this reform to pass, they may have no other choice than renewing the coalition with the elderly-people party. 
[3] Austen-Smith, D., 2000. Redistributing income under Proportional Representation. Journal of Political Economy 108, 1235-1269.

[4] Austen-Smith, D. and J. Banks, 1988. Elections, coalitions, and legislative outcomes. American Political Science Review 82, 405-422.

[5] Austen-Smith, D. and J. Banks, 1989. Electoral accountability and incumbency. In: Models of Strategic Choice in Politics, P. Ordeshook (ed.), University of Michigan Press, Ann Arbor, MI.

[6] Baron, D., 1996. A dynamic theory of collective goods programs. American Political Science Review 90, 316-330.

[7] Baron, D. and D. Diermeier, 2001. Elections, governments, and parliaments in Proportional Representation systems. Quarterly Journal of Economics 116, 933-967.

[8] Baron, D. and J. Ferejohn, 1989. Bargaining in legislatures. American Political Science Review 83, 1181-1206.

[9] Barro, R., 1973. The control of politicians: an economic model. Public Choice $14,19-42$.

[10] Besley, T. and S. Coate, 1998. Sources of inefficiency in a representative democracy: a dynamic analysis. American Economic Review 88, 139-156.

[11] Cho, I. and D. Kreps, 1987. Signalling games and stable equilibria. Quarterly Journal of Economics 102, 179-221.

[12] Coate, S. and S. Morris, 1995. On the form of transfers to special interests. Journal of Political Economy 103, 1210-1235.

[13] Cox, G., 1997. Making Votes Count. Cambridge University Press, Cambridge.

[14] Diermeier, D. and A. Merlo, 2004. An empirical investigation of coalitional bargaining procedures. Journal of Public Economics 88, 783-797.

[15] Drazen, A., 2000. Political Economy in Macroeconomics. Princeton University Press, Princeton, NJ.

[16] Fama, E., 1980. Agency problems and the theory of the firm. Journal of Political Economy 88, 288-307.

[17] Ferejohn, J., 1986. Incumbent performance and electoral control. Public Choice $50,5-25$.

[18] Fernandez, R. and D. Rodrik, 1991. Resistance to reform: Status quo bias in the presence of individual-specific uncertainty. American Economic Review 81, $1146-1155$.

[19] Grilli, V., D. Masciandaro and G. Tabellini, 1991. Political and monetary institutions and public financial policies in the industrial countries. Economic Policy 13, 341-392.

[20] Groseclose, T. and N. McCarty, 2001. The politics of blame: bargaining before an audience. American Journal of Political Science 45, 100-119. 
[21] Holmstrom, B., 1982a. Managerial incentive problems: a dynamic perspective. In: Essays in Economics and Management in Honor of Lars Wahlbeck. Helsinki: Swedish School of Economics.

[22] Holmstrom, B., 1982b. Moral hazard in teams. The Bell Journal of Economics $13,324-340$.

[23] Holmstrom, B. and J. Ricart I Costa, 1986. Managerial incentives and capital management. Quarterly Journal of Economics 101, 835-860.

[24] Laban, R. and F. Sturzenegger, 1994. Distributional conflict, financial adaptations and delayed stabilizations. Economics and Politics 6, 257-276.

[25] Laver, M. and N. Schofield, 1998. Multiparty Government. The Politics of Coalition in Europe. University of Michigan Press, Ann Arbor, MI.

[26] Laver, M. and K.A. Shepsle (eds), 1994. Cabinet Ministers and Parliamentary Government. Cambridge University Press, Cambridge.

[27] Lazear, E., 1989. Pay equality and industrial politics. Journal of Political Economy $97,561-580$.

[28] Milesi-Ferretti, G.M. and E. Spolaore, 1994. How cynical can an incumbent be? Strategic policy in a model of government spending. Journal of Public Economics 55, 121-140.

[29] Morris, S., 2001. Political correctness. Journal of Political Economy 109, 231265.

[30] Muller, W. and K. Strom (eds), 2000. Coalition Governments in Western Europe. Oxford University Press, Oxford.

[31] Olson, M., 1982. The Rise and Decline of Nations. Yale University Press, New Haven, CT.

[32] Prendergast, C. and L. Stole, 1996. Impetuous youngsters and jaded old-timers: acquiring a reputation for learning. Journal of Political Economy 104, 11051134.

[33] Rogoff, K., 1990. Equilibrium political budget cycles. American Economic Review 80, 21-36.

[34] Rogoff, K. and A. Sibert, 1988. Elections and macroeconomic policy cycles. Review of Economic Studies 55, 1-16.

[35] Roubini, N. and J. Sachs, 1989. Political and economic determinants of budget deficits in the industrial democracies. European Economic Review 33, 903-938.

[36] Scharfstein, D. and J. Stein, 1990. Herd behavior and investment. American Economic Review 80, 465-479. 


\section{APPENDIX}

Let's first introduce some extra notation. Let $v^{i}\left(g_{1}, r_{1}\right)$ be party $i$ 's vote total given the first-period policy outcome $p_{1}=\left(g_{1}, r_{1}\right)$. Also let $\sigma_{2}^{i}\left(j^{i}\right)$ be the probability that in the second period party $i$ proposes the reform to be in place, and $\gamma_{2}^{i}\left(\mathcal{C}_{2}, g_{1}\right)$ be the level of public spending party $i$ proposes in the second period when the government is $\mathcal{C}_{2}$ and the status quo level of public spending $g_{1}$. Also whenever it is possible to do so without causing a confusion, I shall denote the voting strategy and period- $t$ utility of citizen $n$ as $\alpha^{n}\left(. ; p_{1}\right)$ and $u^{n}\left(p_{t}\right)$, respectively.

I now state and prove two additional lemmas which will be used in the proofs of the propositions stated above.

Lemma 1. If $v^{i}\left(g^{M}, r_{1}\right)<\frac{N+1}{2}$ for all $i \in I$, then the unique second-period policy outcome is $p_{2}=\left(g^{M}, 1\right)$ if $\#\left\{i \in I: j^{i}=P\right\} \geq 2$ and $p_{2}=\left(g^{M}, 0\right)$ otherwise.

Proof. I prove the result via the following three claims.

Claim 1 Suppose $p_{1}=\left(g^{M}, 0\right)$ and $\# \mathcal{C}_{2} \geq 2$. Then $p_{2}=\left(g^{M}, 1\right)$ if $j^{i}=P$ for all $i \in \mathcal{C}_{2}$, otherwise $p_{2}=\left(g^{M}, 0\right)$.

Proof of Claim 1. Since the second period is the last one, neither party has a reputational incentive to propose a reform outcome different from its ideal one, i.e. $\sigma_{2}^{i}\left(j^{i}\right)=r^{i}$ for all $i \in I$. Given that $r_{1}=0, r_{2}=1$ only if all second-period coalition members choose to adopt the reform. This occurs only if $j^{i}=P$ for all $i \in \mathcal{C}_{2}$. Otherwise, $r_{2}=0$.

That $g_{2}=g^{M}$ follows from $\mathcal{P}\left(\mathcal{C}_{2}, g^{M}\right)=\left\{g^{M}\right\}$ for all $\mathcal{C}_{2} \subseteq I$ with $\# \mathcal{C}_{2} \geq 2$.

Claim 2 Suppose $p_{1}=\left(g^{M}, 1\right)$ and $\# \mathcal{C}_{2} \geq 2$. Then $p_{2}=\left(g^{M}, 1\right)$ if there exists $i \in$ $\mathcal{C}_{2}$ with $j^{i}=P$, otherwise $p_{2}=\left(g^{M}, 0\right)$.

Proof of Claim 2. Obvious.

Claim 3 Suppose $v^{i}\left(g^{M}, r_{1}\right)<\frac{N+1}{2}$ for all $i \in I$. Then $\# \mathcal{C}_{2}=2$. Moreover, if $p_{1}=\left(g^{M}, 0\right)$, then $j^{i}=P$ for all $i \in \mathcal{C}_{2}$ if and only if $\#\left\{i \in I: j^{i}=P\right\} \geq 2$. Instead if $p_{1}=\left(g^{M}, 1\right)$, then $j^{i}=A$ for all $i \in \mathcal{C}_{2}$ if and only if $\#\left\{i \in I: j^{i}=A\right\} \geq$ 2.

Proof of Claim 3. That $\# \mathcal{C}_{2}=2$ follows from ego rents decreasing with the number of parties in the coalition and each party having veto power.

Let $S \equiv\left\{i \in I: j^{i}=P\right\}$. If $\# S=3$ or $=0$, it is trivial.

Suppose $\# S=2$. Note that $g_{1}=g^{M}$ implies $\mathcal{P}\left(\mathcal{C}_{2}, g_{1}\right)=\left\{g^{M}\right\}$, and thus $g_{2}=g^{M}$ for all $\mathcal{C}_{2} \in \mathcal{W}_{\mathcal{C}}$. First suppose $r_{1}=0$. Then for any $\mathcal{C}_{2} \in \mathcal{W}_{\mathcal{C}}$ with $k \in \mathcal{C}_{2}$ and $k \notin S, r_{2}=0$ (since $\sigma_{2}^{k}(A)=0$ ). Instead if $k \notin \mathcal{C}_{2}$, then $j^{i}=P$ for all $i \in \mathcal{C}_{2}$, and $r_{2}=1$ (since $\left.\sigma_{2}^{i}(P)=1\right)$. Given that $u_{P}^{i}\left(g^{M}, 1, m_{2}\right)>u_{P}^{i}\left(g^{M}, 0, m_{2}\right)$ for all $i \in S$, we thus have $\mathcal{C}_{2}=S$ and $p_{2}=\left(g^{M}, 1\right)$. Indeed, if party $i \in S$ is the first to be appointed as the formateur, it proposes party $h \in S, h \neq i$, to join it in a coalition, and party $h$ accepts. Instead if party $k \notin S$ is the first to be appointed as the formateur, then the other two parties are better off rejecting its offer since they anticipate that one of them will then be appointed as the formateur and will propose the other one to join it in the second-period government.

Suppose instead $r_{1}=1$. Then for any $\mathcal{C}_{2} \in \mathcal{W}_{\mathcal{C}}$, there exists $i \in \mathcal{C}_{2}$ such that $j^{i}=P$. Hence that party vetoes the repeal of the reform, and thus $p_{2}=\left(g^{M}, 1\right)$ for all $\mathcal{C}_{2} \in \mathcal{W}_{\mathcal{C}}$.

It remains to consider the case where $\# S=1$. The argument is similar to the one where $\# S=2$, but with $\mathcal{C}_{2}=I \backslash S$ if $r_{1}=1$. Q.E.D. 
Lemma 2. Suppose $v^{i}\left(g_{1}, 1\right)<\frac{N+1}{2}$ for all $i \in I$ and $\#\left\{i \in I: j^{i}=P\right\} \geq 2$. Then there exists an equilibrium of the subgame where $p_{2}=\left(g^{M}, 1\right)$.

Proof. Let \# $\left\{i \in I: j^{i}=P\right\} \geq 2$ and $v^{i}\left(g_{1}, 1\right)<\frac{N+1}{2}$ for all $i \in I$. Since at least two parties are pro-reform, there is a pro-reform party $i$ in any second-period coalition government $\mathcal{C}_{2}$, which thus vetoes a repeal of the reform. Hence in any equilibrium of the subgame, $r_{2}=1$.

It remains to show that there exists an equilibrium of the subgame where $g_{2}=$ $g^{M}$. Suppose first that $g_{1}<g^{L}$. Define $\widetilde{g}>g^{L}$ the level of public good such that $\left\|g^{L}-\widetilde{g}\right\|=\left\|g^{L}-g_{1}\right\|$. There are two cases to consider. Either $\widetilde{g} \geq g^{M}$, in which case $g^{M} \in \mathcal{P}\left(\mathcal{C}_{2}, g_{1}\right)$ for all $\mathcal{C}_{2} \in \mathcal{W}_{\mathcal{C}}$, and $\gamma_{2}^{i}\left(\mathcal{C}_{2}, g_{1}\right)=g^{M}$ for all $i \in \mathcal{C}_{2}$ is an equilibrium strategy in the second-period policy choice game. Or $\widetilde{g}<g^{M}$. In that case $g^{M} \in \mathcal{P}\left(\{M, R\}, g_{1}\right)$, and $\gamma_{2}^{M}\left(\{M, R\}, g_{1}\right)=\gamma_{2}^{R}\left(\{M, R\}, g_{1}\right)=g^{M}$ are equilibrium strategies in the second-period policy choice game (in fact $g_{2}=g^{M}$ is also the Nash Bargaining solution here). In the same time $\mathcal{P}\left(\mathcal{C}_{2}, g_{1}\right)=\left[g^{L}, \widetilde{g}\right]$ for all $\mathcal{C}_{2} \in \mathcal{W}_{\mathcal{C}}$ with $L \in \mathcal{C}_{2}$. It follows that parties $M$ and $R$ are strictly better off forming a coalition government together than with party $L$. And thus $\mathcal{C}_{2}=\{M, R\}$ and $p_{2}=\left(g^{M}, 1\right)$ is an equilibrium outcome of the subgame.

Suppose now $g_{1} \in\left[g^{L}, g^{M}\right)$, then $\mathcal{P}\left(\mathcal{C}_{2}, g_{1}\right)=\left\{g_{1}\right\}$ for all $\mathcal{C}_{2} \in \mathcal{W}_{\mathcal{C}}$ with $L \in \mathcal{C}_{2}$, and the same argument as above applies.

If $g_{1}=g^{M}, \mathcal{P}\left(\mathcal{C}_{2}, g^{M}\right)=\left\{g^{M}\right\}$ for all $\mathcal{C}_{2} \in \mathcal{W}_{\mathcal{C}}$ and thus $g_{2}=g^{M}$.

Finally, the case $g_{1}>g^{M}$ is symmetric to the one where $g_{1}<g^{M}$. Q.E.D.

We now turn to proving the propositions.

Proof of Proposition 1. Let $g^{L M} \equiv \frac{g^{L}+g^{M}}{2}$ the mid-point between $g^{L}$ and $g^{M}$, and consider the class of distributions of preference-types $F$ where $F\left(g^{L M}\right)<\frac{N+1}{2}$. Also define $\bar{\theta}$ as follows

$$
\bar{\theta} \equiv \max \left\{\theta^{M}, \theta^{R}, \tilde{\theta}\right\}+\frac{g^{R}-g^{L}}{\beta_{P}}
$$

, where $\widetilde{\theta}$ is the initial belief that at least two parties are pro-reform. Condition $(i)$ and $\theta^{i} \in(0,1)$ for each party $i$ imply $\bar{\theta} \in(0,1)$. Suppose $\theta^{L}>\bar{\theta}$.

I am going to show that there exists a political equilibrium with $p_{1}=\left(g^{M}, 0\right)$ and $p_{2}=\left(g^{L}, r^{L}\right)$ as the policy outcome, with party $L$ winning outright in the election and forming a single-party government in the second period of the game.

Since the second-period policy choice is the last stage of the game, no party $i$ has an incentive to propose a reform outcome different from the one it prefers. Hence $\sigma_{2}^{i}\left(j^{i}\right)=r^{i}$. Also if party $i$ is the only party in office in the second period, it will implement its preferred level of public spending that is, $\gamma_{2}^{i}\left(\{i\}, g_{1}\right)=g^{i}$. Finally letting $\gamma_{2}^{i}\left(\mathcal{C}_{2}, g_{1}\right)$ be any equilibrium public spending strategy for party $i$ whenever $\mathcal{C}_{2} \neq\{i\}$, we have $\left(\sigma_{2}, \gamma_{2}\right)$ is an equilibrium profile of strategies in the second-period policy choice game.

Let the government formation strategies be as described in the paper.

I am now going to show that there exists a SNE of the voting game, and that in any SNE the profile of voting strategies $\alpha$ must be such that: $(i) v^{L}(g, 1)<\frac{N+1}{2}$ for all $g$; $(i i) v^{L}\left(g^{M}, 0\right) \geq \frac{N+1}{2}$; and $(i i i) v^{R}(g, 0) \geq \frac{N+1}{2}$ for all $g \neq g^{M}$. Let $\alpha$ be 
a profile of voting strategies such that for any pro-reform citizen $n$,

$$
\begin{cases}\alpha^{n}(M ; g, 1)=1 & , \text { for all } g \\ \alpha^{n}\left(L ; g^{M}, 0\right)=1 & \\ \alpha^{n}(R ; g, 0)=1 & , \text { for all } g \neq g^{M}\end{cases}
$$

, and for any anti-reform citizen $n$ and all $g$,

$$
\left\{\begin{array}{l}
\alpha^{n}(R ; g, 1)=1 \\
\alpha^{n}(M ; g, 0)=1
\end{array}\right.
$$

Also let the beliefs be as described in the paper.

I now prove the result via a sequence of three claims.

Claim $1 v^{L}\left(g^{M}, 0\right) \geq \frac{N+1}{2}$.

Proof of Claim 1. Let $p_{1}=\left(g^{M}, 0\right)$. Given $\alpha, v^{L}\left(g^{M}, 0\right) \geq \frac{N+1}{2}$. Hence $\mathcal{C}_{2}=\{L\}$, and citizens anticipate $g_{2}=g^{L}$ and $r_{2}=1$ (0, resp.) with probability $\theta^{L}\left(1-\theta^{L}\right.$, resp.).

To show that $\alpha$ is an equilibrium profile of voting strategies and $v^{L}\left(g^{M}, 0\right) \geq$ $\frac{N+1}{2}$ the unique SNE outcome of the voting game, it is sufficient to show that neither of the pro-reform citizens prefer to the lottery $\left(g^{L}, \theta^{L}\right)$ any of the other lotteries: $(i)\left(g^{M}, \theta^{M}\right)$, the expected lottery if $v^{M}\left(g^{M}, 0\right) \geq \frac{N+1}{2} ;(i i)\left(g^{R}, \theta^{R}\right)$, the expected lottery if $v^{R}\left(g^{M}, 0\right) \geq \frac{N+1}{2}$; or $(i i i)\left(g^{M}, \widetilde{\theta}\right)$, the expected lottery if $v^{i}\left(g^{M}, 0\right)<\frac{N+1}{2}$ for all $i \in I$ (by lemma 1). Letting $\widehat{\theta} \equiv \max \left\{\theta^{M}, \theta^{R}, \widetilde{\theta}\right\}$, a sufficient condition is that for all pro-reform citizens,

$$
-\left\|g^{\ell}-g^{L}\right\|+\theta^{L} \beta_{P}>\max _{g \in\left\{g^{M}, g^{R}\right\}}\left\{-\left\|g^{\ell}-g\right\|\right\}+\widehat{\theta} \beta_{P}
$$

, or $\theta^{L}>\widehat{\theta}+\frac{g^{R}-g^{L}}{\beta_{P}}$. Since the RHS of this latter inequality is $\bar{\theta}$, and that $\theta^{L}>\bar{\theta}$, the condition is satisfied.

Claim $2 v^{L}(g, 1)<\frac{N+1}{2}$ for all $g \in[0,1]$.

Proof of Claim 2. Let $p_{1}=(g, 1)$. Given $\alpha, v^{M}(g, 1) \geq \frac{N+1}{2}$ and thus $v^{L}(g, 1)<\frac{N+1}{2}$. Hence $\mathcal{C}_{2}=\{M\}$, and citizens anticipate $g_{2}=g^{M}$ and $r_{2}=1$. To show that $\alpha$ is an equilibrium profile of voting strategies it is sufficient to show that there is no coalition of voters which is sufficiently large and would prefer any of the other lotteries: $(i)\left(g^{L}, 1\right)$, the expected lottery if $v^{L}(g, 1) \geq \frac{N+1}{2} ;(i i)\left(g^{R}, \theta^{R}\right)$, the expected lottery if $v^{R}(g, 1) \geq \frac{N+1}{2}$; or $($ iii $)\left(g^{M}, 1\right)$, the expected lottery if $v^{i}(g, 1)<\frac{N+1}{2}$ for all $i \in I$ (by lemma 2). This holds given $F\left(g^{L M}\right)<\frac{N+1}{2}$ and $\theta^{R}<1-\frac{g^{R}-g^{M}}{\beta_{P}}$ (the latter inequality by assumption $\left.1(i i)\right)$. Hence there exists a SNE of the voting game where $v^{L}(g, 1)<\frac{N+1}{2}$.

It remains to show that $v^{L}(g, 1)<\frac{N+1}{2}$ in any SNE. Suppose on the contrary that there exists an equilibrium profile of voting strategies $\bar{\alpha}$ where party $L$ gets a majority of votes. It follows that $\mathcal{C}_{2}=\{L\}$, and citizens anticipate $g_{2}=g^{L}$ and $r_{2}=1$. Now construct a profile of voting strategies $\widetilde{\alpha}$ where $\widetilde{\alpha}^{n}(M ; g, 1)=1$ for all citizens $n$ with $g^{n}>g^{L M}$, and $\widetilde{\alpha}^{n}=\bar{\alpha}^{n}$ otherwise. Since $F\left(g^{L M}\right)<\frac{N+1}{2}$ party $M$ thus gets a majority of votes when $p_{1}=(g, 1)$. It is easy to see that any citizen $n$ 
with $\widetilde{\alpha}^{n}(M ; g, 1)=1$ then gets a strictly higher expected second-period utility than under $\bar{\alpha}$, which contradicts $\bar{\alpha}$ an equilibrium profile of voting strategies. Hence in any SNE of the voting game $v^{L}(g, 1)<\frac{N+1}{2}$.

Claim $3 v^{R}(g, 0) \geq \frac{N+1}{2}$ for all $g \neq g^{M}$.

Proof of Claim 3. Similar to the proof of Claim 1, with $\theta^{R}>\frac{g^{R}-g^{L}}{\beta_{P}}$ a sufficient condition for $v^{R}(g, 0) \geq \frac{N+1}{2}, g \neq g^{M}$, to be the unique SNE outcome of the voting game (this condition holds by assumption $1(i i)$ ).

It remains to show that $p_{1}=\left(g^{M}, 0\right)$ is an equilibrium outcome of the firstperiod policy choice game. Let $\left(\sigma_{1}, \gamma_{1}\right)$ be any weakly undominated profile of strategies in the first-period policy game, with $\sigma_{1}^{L}(\mathcal{J})=\sigma_{1}^{M}\left(j^{L}, A, j^{R}\right)=0$ and $\gamma_{1}^{L}(\mathcal{J}, 0)=g^{M}$ for all $\mathcal{J} \in\{P, A\}^{3}$. The next two claims show that $\left(\sigma_{1}, \gamma_{1}\right)$ is an equilibrium profile.

Claim $4 \gamma_{1}^{L}(\mathcal{J}, 0)=g^{M}$ for all $\mathcal{J} \in\{P, A\}^{3}$.

Proof of Claim 4. Suppose $r_{1}=0$. I have to show that $\gamma_{1}^{L}(\mathcal{J}, 0)=g^{M}$ is a best response to $\gamma_{1}^{M}(\mathcal{J}, 0)$. Suppose party L proposes $g_{1}=g^{M}$, then $p_{1}=\left(g^{M}, 0\right)$ and $v^{L}\left(g^{M}, 0\right) \geq \frac{N+1}{2}$ (by Claim 1$)$. Party L's intertemporal utility is thus equal to $U_{j}^{L}\left(g^{M}, 0\right)=-\left\|g^{L}-g^{M}\right\|+m_{2}+\delta\left(\beta_{j} r^{L}+m_{1}\right)$, where $r^{L}$ is party L's preferred reform outcome. Now suppose instead that party $L$ proposes $g \neq g^{M}$. Either party M proposes $\bar{g} \neq g$, and thus $g_{1}=g^{M}$ (since $g_{0}=g^{M}$ ). Or, party M proposes $\bar{g}=g$ in which case $g_{1}=g$ and $v^{R}(g, 0) \geq \frac{N+1}{2}$ (by Claim 3). The maximal intertemporal utility party $L$ can then get is equal to $\max U_{j}^{L}(g, 0)=m_{2}+\delta\left(-\left\|g^{L}-g^{R}\right\|+\beta_{j} r^{L}\right)$ (which would happen if $g_{1}=g^{L}$ and $r^{R}=r^{L}$ ). Thus, a sufficient condition for party $\mathrm{L}$ not having an incentive to deviate is

$$
-\left\|g^{L}-g^{M}\right\|+m_{2}+\delta\left(\beta_{j} r^{L}+m_{1}\right) \geq m_{2}+\delta\left(-\left\|g^{L}-g^{R}\right\|+\beta_{j} r^{L}\right)
$$

, or $\delta m_{1} \geq\left(g^{M}-g^{L}\right)-\delta\left(g^{R}-g^{L}\right)$, which is satisfied by condition (ii).

Claim $5 \sigma_{1}^{L}(\mathcal{J})=\sigma_{1}^{M}\left(j^{L}, A, j^{R}\right)=0$ for all $\mathcal{J} \in\{P, A\}^{3}$.

Proof of Claim 5. (1) Consider first a pro-reform party L. If it chooses to veto the adoption of the reform, then $r_{1}=0$ and by Claim $4, g_{1}=g^{M}$. By Claim 1, we have $v^{L}\left(g^{M}, 0\right) \geq \frac{N+1}{2}$ and party L's intertemporal utility is thus equal to $U_{P}^{L}\left(g^{M}, 0\right)=-\left\|g^{L}-g^{M}\right\|+m_{2}+\delta\left(\beta_{P}+m_{1}\right)$. Rather if it deviates and implement the reform, then with probability $(1-\pi)$, party $\mathrm{M}$ vetoes the adoption of the reform and $r_{1}=0$. But with probability $\pi, r_{1}=1$ and $v^{M}(g, 1) \geq \frac{N+1}{2}$. The maximum intertemporal utility party $\mathrm{L}$ can get is $\max U_{P}^{L}(g, 1)=\beta_{P}+m_{2}+\delta \beta_{P}$ (which would happen if $g_{1}=g^{L}$ ). A sufficient condition for a pro-reform party L not having an incentive to deviate from $\sigma_{1}^{L}\left(P, j^{M}, j^{R}\right)=0$ is

$$
U_{P}^{L}\left(g^{M}, 0\right) \geq(1-\pi) U_{P}^{L}\left(g^{M}, 0\right)+\pi \max U_{P}^{L}(g, 1)
$$

, or $\delta m_{1} \geq \beta_{P}+\left(g^{M}-g^{L}\right)$. The latter inequality is satisfied by condition (ii).

(2) Consider now an anti-reform party L. The logic is the same as for a proreform party L but with $U_{A}^{L}\left(g^{M}, 0\right)=-\left\|g^{L}-g^{M}\right\|+m_{2}+\delta m_{1}$ and $\max U_{A}^{L}(g, 1)=$ $\beta_{A}+m_{2}$. Hence a sufficient condition for an anti-reform party $\mathrm{L}$ not having an incentive to deviate from $\sigma_{1}^{L}\left(A, j^{M}, j^{R}\right)=0$ is $\delta m_{1} \geq \beta_{A}+\left(g^{M}-g^{L}\right)$, which is satisfied since $\beta_{A}<0<\beta_{P}$. 
(3) Finally, consider an anti-reform party $\mathrm{M}^{38}$ If it vetoes the adoption of the reform, $r_{1}=0, g_{1}=g^{M}$ and $v^{L}\left(g^{M}, 0\right) \geq \frac{N+1}{2}$. As a result, its minimal intertemporal utility is equal to $\min U_{A}^{M}\left(g^{M}, 0\right)=m_{2}+\delta\left(-\left\|g^{M}-g^{L}\right\|+\beta_{A}\right)$ (which would happen if $j^{L}=P$ ). Rather, if it deviates and implements the reform, then with probability $(1-\pi)$, party $L$ vetoes the adoption of the reform and $r_{1}=0$. But with probability $\pi, r_{1}=1$ and $v^{M}(g, 1) \geq \frac{N+1}{2}$. Therefore, party M's intertemporal utility is $U_{A}^{M}\left(g^{M}, 1\right)=\beta_{A}+m_{2}+\delta m_{1}$. Hence, a sufficient condition for party $\mathrm{M}$ not having an incentive to deviate from $\sigma_{1}^{M}\left(j^{L}, A, j^{R}\right)=0$ is $\left|\beta_{A}\right| \geq \frac{\delta}{1-\delta}\left(m_{1}+g^{M}-g^{L}\right)$, which is satisfied by assumption $1(i)$. Q.E.D.

Proof of Proposition 2. Consider the class of distributions of preference types $F$ that satisfy the following conditions: (a) $F\left(g^{L M}\right)<\frac{N+1}{2}$; (b) $N_{A}>\max \left\{F_{P}\left(g^{M}\right)\right.$, $\left.N_{P}-F_{P}\left(g^{M}\right)\right\} ;(c)\left[F_{P}\left(g^{M}\right)+F_{A}\left(g^{L M}+\left(\frac{\widetilde{\theta}-\theta^{L}}{2}\right)\left|\beta_{A}\right|\right)\right]<\frac{N+1}{2}$; and $(d)\left[\widehat{F}_{P}\left(g^{M}\right)+\right.$ $\left.\widehat{F}_{A}\left(g^{M R}+\left(\frac{\theta^{R}-\widetilde{\theta}}{2}\right)\left|\beta_{A}\right|\right)\right] \geq \frac{N+1}{2}$, where $\widehat{F}_{j}(g) \equiv \#\left\{n: j^{n}=j\right.$ and $\left.g^{n}<g\right\}$ for $j \in\{P, A\}$ and $g^{M R}=\frac{g^{M}+g^{R}}{2}$. Also define $\bar{\theta}$ as follows

$$
\bar{\theta} \equiv \max \left\{0, \max _{k \in\{L, R\}}\left\{\widetilde{\theta}-\frac{\left|g^{k}-g^{M}\right|}{\left|\beta_{A}\right|}\right\}\right\} .
$$

Suppose $\theta^{M}<\tilde{\theta}$ (this holds by condition $(i)$ ) and $\min \left\{\theta^{L}, \theta^{R}\right\}>\bar{\theta}$.

I am now going to show that there exists a political equilibrium with $p_{1}=$ $\left(g^{M}, 0\right)$ and $p_{2}=\left(g^{M}, 1\right)$ if at least two parties are pro-reform, and $p_{1}=p_{2}=$ $\left(g^{M}, 0\right)$ otherwise.

Since the second-period policy choice is the last stage of the game neither party has an incentive to propose a reform outcome different from the one it prefers. Hence $\sigma_{2}^{i}\left(j^{i}\right)=r^{i}$ for any party $i$. Also if $g_{1}=g^{M}$ proposing its ideal level of public spending that is, $\gamma_{2}^{i}\left(\mathcal{C}_{2}, g^{M}\right)=g^{i}$, is an equilibrium strategy for each party $i$. Finally letting $\gamma_{2}^{i}\left(\mathcal{C}_{2}, g_{1}\right)$ be an arbitrary equilibrium strategy for party $i$ whenever $g_{1} \neq g^{M}$, we have that $\left(\sigma_{2}, \gamma_{2}\right)$ is an equilibrium profile of strategies in the second-period policy choice game.

Let the government formation strategies be as described in the paper, and satisfy lemmas 1 and 2 .

I am now going to show that there exists a SNE of the voting game where the electoral outcome is such that: $(i) v^{M}(g, 1) \geq \frac{N+1}{2}$ for all $g$; $(i i) v^{i}\left(g^{M}, 0\right)<\frac{N+1}{2}$ for any party $i$; and $(i i i) v^{R}(g, 0) \geq \frac{N+1}{2}$ for all $g \neq g^{M}$. Let $\alpha$ be the profile of voting strategies described in the proof of Proposition 1 except that $\alpha^{n}\left(R ; g^{M}, 0\right)=$ 1 for all pro-reform citizens $n$ with $g^{n}>g^{M}$. Hence the proof is similar to Claims 2 and 3 in the proof of Proposition 1 when $p_{1} \neq\left(g^{M}, 0\right)$. We thus only have to prove that $\alpha\left(. ; g^{M}, 0\right)$ is a SNE profile of voting strategies. This is done in the following claim.

Claim $1 \alpha\left(. ; g^{M}, 0\right)$ is an equilibrium profile of voting strategies.

Proof of Claim 1. Let $p_{1}=\left(g^{M}, 0\right)$. Given the class of distributions of preference types $F, 0<v^{i}\left(g^{M}, 0\right)<\frac{N+1}{2}$ for any party $i$, and $v^{M}\left(g^{M}, 0\right)>$

\footnotetext{
${ }^{38}$ Note that since $\sigma_{1}^{L}(\mathcal{J})=0$ for all $\mathcal{J} \in\{P, A\}^{3}, r_{1}=0$ whatever party M's decision. But remember that we have imposed incumbents' strategies to be weakly undominated. Hence, we still have to show that $\sigma_{1}^{M}\left(j^{L}, A, j^{R}\right)=0$ is an equilibrium strategy.
} 
$\max \left\{v^{L}\left(g^{M}, 0\right), v^{R}\left(g^{M}, 0\right)\right\}$. Hence $\# \mathcal{C}_{2}=2$, and citizens anticipate $g_{2}=g^{M}$ and $r_{2}=1$ ( 0 , resp.) with probability $\widetilde{\theta}(1-\widetilde{\theta}$, resp.).

For $\alpha$ to be an equilibrium profile of voting strategies when $p_{1}=\left(g^{M}, 0\right)$, it must be that there is no coalition of voters who are pivotal and want to deviate, i.e. no coalition of voters who prefer one of the following lotteries over the second-period policy outcome is pivotal: $(i)\left(g^{L}, \theta^{L}\right)$, the expected lottery if $v^{L}\left(g^{M}, 0\right) \geq \frac{N+1}{2}$; (ii) $\left(g^{M}, \theta^{M}\right)$, the expected lottery if $v^{M}\left(g^{M}, 0\right) \geq \frac{N+1}{2}$; or $(i i i)\left(g^{R}, \theta^{R}\right)$, the expected lottery if $v^{R}\left(g^{M}, 0\right) \geq \frac{N+1}{2}$.

Consider first the coalition of voters who might prefer party $L$ to win outright. For any such citizen $n$ it must be that

$$
-\left\|g^{n}-g^{L}\right\|+\theta^{L} \beta^{n} \geq-\left\|g^{n}-g^{M}\right\|+\tilde{\theta} \beta^{n} .
$$

If citizen $n$ is pro-reform, this inequality together with condition $(i)$ imply $g^{n}<$ $g^{M}$. And if citizen $n$ is anti-reform, $\theta^{L}>\bar{\theta}$ implies that this inequality can hold only if $\left(\theta^{L}-\widetilde{\theta}\right) \leq \frac{g^{M}-g^{L}}{\left|\beta_{A}\right|}$ and $g^{n} \leq g^{L M}+\frac{\left(\widetilde{\theta}-\theta^{L}\right) \cdot\left|\beta_{A}\right|}{2}$. But given $F$ this coalition of citizens is not pivotal for party $L$ getting a majority of votes.

Since $\theta^{M}<\widetilde{\theta}$ only the anti-reform citizens want party $M$ to win outright, and they already vote for that party. Hence no coalition of voters is pivotal for party $M$ getting a majority of votes and is willing to deviate in order to achieve this. Finally proceeding as we did for party $L$, it is possible to show that, given condition (d) on $F$, the coalition of citizens who might prefer party $R$ to win outright is not pivotal.

Those three cases exhaust all possibilities. Hence there is no coalition of voters who are pivotal and want to deviate. Therefore $\alpha$ is an equilibrium profile of voting strategies when $p_{1}=\left(g^{M}, 0\right)$.

It remains to show that $p_{1}=\left(g^{M}, 0\right)$ is an equilibrium outcome of the firstperiod policy choice game. Let $\left(\sigma_{1}, \gamma_{1}\right)$ be any profile of weakly undominated strategies, with $\sigma_{1}^{L}(\mathcal{J})=\sigma_{1}^{M}\left(j^{L}, A, j^{R}\right)=0$ and $\gamma_{1}^{M}\left(\mathcal{J}, r_{1}\right)=g^{M}$ for all $r_{1} \in$ $\{0,1\}$ and $\mathcal{J} \in\{P, A\}^{3}$. The next two claims show that those are equilibrium strategies in the first-period policy choice game.

Claim $2 \gamma_{1}^{M}\left(\mathcal{J}, r_{1}\right)=g^{M}$ for all $r_{1} \in\{0,1\}$ and $\mathcal{J} \in\{P, A\}^{3}$ is a best response to $\gamma_{1}^{L}\left(\mathcal{J}, r_{1}\right)$.

Proof of Claim 2. (1) Suppose that $r_{1}=1$. From the voting stage, we have $v^{M}(g, 1) \geq \frac{N+1}{2}$ for all $g$ and party M's intertemporal utility is equal to $U_{j}^{M}(g, 1)=-\left\|g^{M}-g\right\|+\beta_{j}+m_{2}+\delta\left(\beta_{j} r^{M}+m_{1}\right)$. But $U_{j}^{M}(g, 1)$ reaches its (unique) maximum at $g=g^{M}$. Hence, $\gamma_{1}^{M}(\mathcal{J}, 1)=g^{M}$ is a best response to $\gamma_{1}^{L}(\mathcal{J}, 1)$ for all $\mathcal{J} \in\{P, A\}^{3}$.

(2) Suppose that $r_{1}=0$. Consider first a pro-reform party M. If it proposes $g^{M}$, then $g_{1}=g^{M}$. It follows that $\frac{N-1}{2} \geq v^{M}\left(g^{M}, 0\right)>\max \left\{v^{L}\left(g^{M}, 0\right), v^{R}\left(g^{M}, 0\right)\right\}$, which implies $\# \mathcal{C}_{2}=2$ and $M \in \mathcal{C}_{2}$ (if $j^{L}=j^{R}, \mathcal{C}_{2}=\{L, M\}$ with probability $1 / 2$ and $\mathcal{C}_{2}=\{M, R\}$ with probability $1 / 2$. Otherwise, $\mathcal{C}_{2}=\{M, k\}$ with $k \in I$ and $\left.j^{k}=P\right)$. Party M's intertemporal utility will be $U_{P}^{M}\left(g^{M}, 0\right)=(1+\delta) m_{2}$ if $j^{L}=j^{R}=A$, and $U_{P}^{M}\left(g^{M}, 0\right)=m_{2}+\delta\left(\beta_{P}+m_{2}\right)$ otherwise. Instead, suppose that party $\mathrm{M}$ deviates and proposes $g \neq g^{M}$. Either party L proposes $\widehat{g} \neq g$, and $g_{1}=g^{M}$. Or party L proposes $g$, and thus $g_{1}=g$. From the voting stage we have $v^{R}(g, 0) \geq \frac{N+1}{2}$, and party M's intertemporal utility is equal to $U_{P}^{M}(g, 0)=$ $-\left\|g^{M}-g\right\|+m_{2}+\delta\left(-\left\|g^{M}-g^{R}\right\|+\beta_{P} r^{R}\right)$. For all $\left(j^{L}, j^{R}\right) \in\{P, A\}^{2}$, we have 
that $U_{P}^{M}\left(g^{M}, 0\right)>U_{P}^{M}(g, 0)$ for all $g \neq g^{M}$. Hence, a pro-reform party $\mathrm{M}$ has no incentive to deviate from $\gamma_{1}^{M}\left(j^{L}, P, j^{R}, 0\right)=g^{M}$.

Consider now an anti-reform party M. If there exists $k \in\{L, R\}$ such that $j^{k}=A$, then the argument is similar to the one for a pro-reform party M. Suppose instead that $j^{L}=j^{R}=P$. If party M proposes $g^{M}$, then $g_{1}=g^{M}$. From the voting stage and lemma 1 , we have that $\mathcal{C}_{2}=\{L, R\}$ and $p_{2}=\left(g^{M}, 1\right)$. Hence, party M's intertemporal utility is equal to $U_{A}^{M}\left(g^{M}, 0\right)=m_{2}+\delta \beta_{A}$. Instead, if parties L and $\mathrm{M}$ agree on $g_{1} \neq g^{M}$, then $v^{R}\left(g_{1}, 0\right) \geq \frac{N+1}{2}, \mathcal{C}_{2}=\{R\}$ and $p_{2}=\left(g^{R}, 1\right)$. Party M's intertemporal utility is then equal to $U_{A}^{M}(g, 0)=-\left\|g^{M}-g\right\|+m_{2}+$ $\delta\left(-\left\|g^{M}-g^{R}\right\|+\beta_{A}\right)$, which is strictly lower than $U_{A}^{M}\left(g^{M}, 0\right)$. Hence, an antireform party $\mathrm{M}$ has no incentive to deviate from $\gamma_{1}^{M}\left(j^{L}, A, j^{R}, 0\right)=g^{M}$.

Claim $3 \sigma_{1}^{L}(\mathcal{J})=\sigma_{1}^{M}\left(j^{L}, A, j^{R}\right)=0$ for all $\mathcal{J} \in\{P, A\}^{3}$.

Proof of Claim 3. (1) Consider first a pro-reform party L. If it vetoes the adoption of the reform in period 1 , then $r_{1}=0, g_{1}=g^{M}$ (by Claim 2) and $v^{i}\left(g^{M}, 0\right)<\frac{N+1}{2}$ for all $i \in I$. As a result, party L's intertemporal utility is at least $\min E U_{P}^{L}\left(g^{M}, 0\right)=-\left\|g^{L}-g^{M}\right\|+m_{2}+\delta\left(-\left\|g^{L}-g^{M}\right\|+\beta_{P} r^{M}+\frac{m_{2}}{2}\right){ }^{39}$ Now if party L implements the reform, then with probability $(1-\pi)$, party $\mathrm{M}$ vetoes the adoption of the reform and $r_{1}=0$. But with probability $\pi$, party $\mathrm{M}$ proposes to adopt the reform. In that case, $p_{1}=\left(g^{M}, 1\right)$ and $v^{M}\left(g^{M}, 1\right) \geq \frac{N+1}{2}$. Party L's intertemporal utility is thus equal to $U_{P}^{L}\left(g^{M}, 1\right)=-\left\|g^{L}-g^{M}\right\|+\beta_{P}+$ $m_{2}+\delta\left(-\left\|g^{L}-g^{M}\right\|+\beta_{P} r^{M}\right)$. Hence, a sufficient condition for a pro-reform party $\mathrm{L}$ not having an incentive to deviate from $\sigma_{1}^{L}\left(P, j^{M}, j^{R}\right)=0$ is $\delta \frac{m_{2}}{2} \geq \beta_{P}$, which holds by condition (ii).

(2) Consider an anti-reform party L. There are three cases to consider. First, let $j^{M}=j^{R}=P$. If party $\mathrm{L}$ vetoes the adoption of the reform, then $\mathcal{C}_{2}=$ $\{M, R\}$ and $U_{A}^{L}\left(g^{M}, 0\right)=-\left\|g^{L}-g^{M}\right\|+m_{2}+\delta\left(-\left\|g^{L}-g^{M}\right\|+\beta_{A}\right)$. Instead if both party $\mathrm{L}$ and party $\mathrm{M}$ decide to implement the reform, then $r_{1}=1, \mathcal{C}_{2}=$ $\{M\}$ and $U_{A}^{L}\left(g^{M}, 1\right)=-\left\|g^{L}-g^{M}\right\|+\beta_{A}+m_{2}+\delta\left(-\left\|g^{L}-g^{M}\right\|+\beta_{A}\right)$. Since $U_{A}^{L}\left(g^{M}, 0\right)>U_{A}^{L}\left(g^{M}, 1\right)$, an anti-reform party $\mathrm{L}$ has no incentive to deviate. Second, let $j^{M}=P$ and $j^{R}=A$. Then, we have $\mathcal{C}_{2}=\{L, M\}$ with probability $1 / 2$ and $\{M, R\}$ with probability $1 / 2$. Party L's intertemporal utility is thus equal to $E U_{A}^{L}\left(g^{M}, 0\right)=-\left\|g^{L}-g^{M}\right\|+m_{2}+\delta\left(-\left\|g^{L}-g^{M}\right\|+\frac{m_{2}}{2}\right)$, and $E U_{A}^{L}\left(g^{M}, 0\right)>U_{A}^{L}\left(g^{M}, 1\right)$. Third, let $j^{M}=A$. Then $E U_{A}^{L}\left(g^{M}, 0\right)$ is the same as above but now $U_{A}^{L}\left(g^{M}, 1\right)=-\left\|g^{L}-g^{M}\right\|+\beta_{A}+m_{2}+\delta\left(-\left\|g^{L}-g^{M}\right\|\right)$. Again, $E U_{A}^{L}\left(g^{M}, 0\right)>U_{A}^{L}\left(g^{M}, 1\right)$. Hence, an anti-reform party $\mathrm{L}$ has no incentive to deviate from $\sigma_{1}^{L}\left(A, j^{M}, j^{R}\right)=0$.

(3) It remains to consider an anti-reform party $M$. There are two cases to consider: $(i) j^{L}=j^{R}=P$; and $(i i) j^{k}=A$ for some $k \in\{L, R\}$. In the first case, if party $\mathrm{M}$ vetoes the adoption of the reform, then $\mathcal{C}_{2}=\{L, R\}$ and $U_{A}^{M}\left(g^{M}, 0\right)=m_{2}+\delta \beta_{A}$. Instead, if the reform is implemented in the first period, then $v^{M}\left(g^{M}, 1\right) \geq \frac{N+1}{2}$ and party M's intertemporal utility is equal to $U_{A}^{M}\left(g^{M}, 1\right)=\beta_{A}+m_{2}+\delta m_{1}$. Hence, party $\mathrm{M}$ has no incentive to deviate from $\sigma_{1}^{M}\left(j^{L}, A, j^{R}\right)=0$ if $\left|\beta_{A}\right| \geq \frac{\delta}{1-\delta} m_{1}$, which holds by assumption $1(i)$. In the second case, if party $\mathrm{M}$ vetoes the adoption of the reform, then $M \in \mathcal{C}_{2}$ and $U_{A}^{M}\left(g^{M}, 0\right)=m_{2}+\delta m_{2}$. As a result, party $\mathrm{M}$ has no incentive to deviate if

\footnotetext{
${ }^{39}$ If $\mathcal{J}=(P, P, P)$ or $\mathcal{J}=(P, A, A)$, then $\operatorname{prob}\left(L \in \mathcal{C}_{2}\right)=\frac{1}{2}$. If $\mathcal{J}=(P, A, P)$ or $\mathcal{J}=(P, P, A)$, then $\operatorname{prob}\left(L \in \mathcal{C}_{2}\right)=1$.
} 
$\left|\beta_{A}\right| \geq \delta\left(m_{1}-m_{2}\right)$ which is satisfied by assumption $1(i)$. Q.E.D.

Proof of Proposition 3. Consider a class of distributions of preference types $F$ that satisfy the following conditions: $(a) F\left(g^{L M}\right)<\frac{N+1}{2}$; and $(b)\left[F_{P}(x)+F_{A}(y)\right] \geq$ $\frac{N+1}{2}$, where $x=\min _{k \in\{M, R, \mathcal{C}\}}\left\{g^{L k}+\left(\frac{\theta^{L}-\theta^{k}}{2}\right) \beta_{P}\right\}$ with $g^{L \mathcal{C}}=g^{L M}$ and $\theta^{\mathcal{C}}=\widetilde{\theta}$, and $y=\min _{k \in\{M, R, \mathcal{C}\}}\left\{y^{k}\right\}$, where $y^{k}=g^{L k}-\left(\frac{\theta^{L}-\theta^{k}}{2}\right)\left|\beta_{A}\right|$ if $\theta^{L} \geq \theta^{k}-\frac{g^{k}-g^{L}}{\left|\beta_{A}\right|}$ (with $\left.g^{\mathcal{C}}=g^{M}\right)$ and $y^{k}=1$ otherwise. Also define $\underline{\theta}$ and $\bar{\theta}$ as follows

$$
\left\{\begin{array}{l}
\underline{\theta} \equiv \max \left\{0, \max _{k \in\{M, R, \mathcal{C}\}}\left\{\theta^{k}-\frac{\left|g^{k}-g^{L}\right|}{\beta_{P}}\right\}\right\}, \text { and } \\
\bar{\theta} \equiv \min \left\{\min _{k \in\{M, R, \mathcal{C}\}}\left\{\theta^{k}+\frac{\left|g^{k}-g^{L}\right|}{\left|\beta_{A}\right|}\right\}, 1\right\} .
\end{array}\right.
$$

$\underline{\beta}_{P}<\left|\beta_{A}\right|$ (by assumption $1(i)$ and condition $(i i)$ ) and condition $(i)$ imply $0 \leq \underline{\theta}<$ $\bar{\theta} \leq 1$.

Let $\theta^{L} \in(\underline{\theta}, \bar{\theta})$. I am going to show that there exists a political equilibrium with $p_{1}=\left(g^{M}, 0\right)$ and $p_{2}=\left(g^{L}, r^{L}\right)$ as the policy outcome, with party $L$ winning outright in the election and forming a single-party government in the second period.

The proof is similar to the proof of Proposition 1, except for Claim 1. Replace $\alpha\left(. ; g^{M}, 0\right)$ by the following: $\alpha^{n}\left(L ; g^{M}, 0\right)=1$ for all pro-reform citizens $n$ such that $g^{n} \leq \min _{k \in\{M, R, \mathcal{C}\}}\left\{g^{L k}+\left(\frac{\theta^{L}-\theta^{k}}{2}\right) \beta_{P}\right\}$, and $\alpha^{n}\left(L ; g^{M}, 0\right)=1$ for all anti-reform citizens $n$ such that $g^{n} \leq \min _{k \in\{M, R, \mathcal{C}\}}\left\{y^{k}\right\}$, where $y^{k}=g^{L k}-\left(\frac{\theta^{L}-\theta^{k}}{2}\right)\left|\beta_{A}\right|$ if $\theta^{L} \geq$ $\theta^{k}-\frac{g^{k}-g^{L}}{\left|\beta_{A}\right|}$ and $y^{k}=1$ otherwise. It can be shown that $\min _{k \in\{M, R, \mathcal{C}\}}\left\{g^{L k}+\left(\frac{\theta^{L}-\theta^{k}}{2}\right) \beta_{P}\right\}$ is strictly greater than $g^{L}$ given that $\theta^{L}>\underline{\theta}$, and strictly lower than $g^{M}$ since $\theta^{L}<\bar{\theta}$ and $\left|\beta_{A}\right|>\beta_{P}$. Also, we have $\min _{k \in\{M, R, \mathcal{C}\}}\left\{y^{k}\right\}>g^{L}$ since $\theta^{L}<\bar{\theta}$.

Given the class of distributions $F$ defined above, $v^{L}\left(g^{M}, 0\right) \geq \frac{N+1}{2}$. Now it is sufficient to show that none of the citizens who vote for party $L$ strictly prefers to the lottery $\left(g^{L}, \theta^{L}\right)$ they expect when party L gets the absolute majority of votes, any of the other feasible lotteries, i.e. $(i)\left(g^{M}, \theta^{M}\right)$ if $v^{M}\left(g^{M}, 0\right) \geq \frac{N+1}{2} ;(i i)$ $\left(g^{R}, \theta^{R}\right)$ if $v^{R}\left(g^{M}, 0\right) \geq \frac{N+1}{2}$; or $(i i i)\left(g^{M}, \widetilde{\theta}\right)$ if $v^{i}\left(g^{M}, 0\right)<\frac{N+1}{2}$ for all $i \in I$.

Consider first those citizens who are of the pro-reform type. For them to strictly prefer the lottery $\left(g^{M}, \theta^{M}\right)$ to $\left(g^{L}, \theta^{L}\right)$, it must be that

$$
-\left\|g^{n}-g^{M}\right\|+\theta^{M} \beta_{P}>-\left\|g^{n}-g^{L}\right\|+\theta^{L} \beta_{P} .
$$

Now for those citizens $n$ with $g^{n} \leq g^{L}$, it must be that $\theta^{L}<\theta^{M}-\frac{g^{M}-g^{L}}{\beta_{P}}$, which contradicts $\theta^{L}>\underline{\theta}$. For those citizens $n$ with $g^{n} \in\left(g^{L}, g^{M}\right)$, it must be that $g^{n}>g^{L M}+\left(\frac{\theta^{L}-\theta^{M}}{2}\right) \beta_{P}$, again a contradiction since we consider citizens with $g^{n} \leq \min _{k \in\{M, R, \mathcal{C}\}}\left\{g^{L k}+\left(\frac{\theta^{L}-\theta^{k}}{2}\right) \beta_{P}\right\}$. In a similar way, we can show that neither of those citizens prefer $\left(g^{R}, \theta^{R}\right)$ or $\left(g^{M}, \widetilde{\theta}\right)$ to $\left(g^{L}, \theta^{L}\right)$. 
Consider now those citizens who are of the anti-reform type. For them to strictly prefer $\left(g^{M}, \theta^{M}\right)$ to $\left(g^{L}, \theta^{L}\right)$, it must be that

$$
-\left\|g^{n}-g^{M}\right\|+\theta^{M} \beta_{A}>-\left\|g^{n}-g^{L}\right\|+\theta^{L} \beta_{A} .
$$

For those citizens with $g^{n}<g^{L}$, it must be that $\theta^{L}>\theta^{M}+\frac{g^{M}-g^{L}}{\left|\beta_{A}\right|}$, which contradicts $\theta^{L}<\bar{\theta}$. For those with $g^{n} \in\left[g^{L}, g^{M}\right]$, the above condition implies that $g^{n}>g^{L M}-\left(\frac{\theta^{L}-\theta^{M}}{2}\right)\left|\beta_{A}\right|$. Either $\theta^{L} \geq \theta^{M}-\frac{g^{M}-g^{L}}{\left|\beta_{A}\right|}$ in which case this contradicts $g^{n} \leq g^{L M}-\left(\frac{\theta^{L}-\theta^{M}}{2}\right)\left|\beta_{A}\right|$. Or, $\theta^{L}<\theta^{M}-\frac{g^{M}-g^{L}}{\left|\beta_{A}\right|}$ in which case $\left[g^{L M}-\left(\frac{\theta^{L}-\theta^{M}}{2}\right)\left|\beta_{A}\right|\right]>g^{M}$ and the condition requires $g^{n}>g^{M}$, which contradicts $g^{n} \in\left[g^{L}, g^{M}\right]$. Finally, for those with $g^{n}>g^{M}$, the above condition implies $\theta^{L}>\theta^{M}-\frac{g^{M}-g^{L}}{\left|\beta_{A}\right|}$. But then $g^{L M}-\left(\frac{\theta^{L}-\theta^{M}}{2}\right)\left|\beta_{A}\right|<g^{M}$ which contradicts $g^{n}>g^{M}$ and $g^{n} \leq g^{L M}-\left(\frac{\theta^{L}-\theta^{M}}{2}\right)\left|\beta_{A}\right|$. In a similar way, we can show that neither of those citizens prefer $\left(g^{R}, \theta^{R}\right)$ or $\left(g^{M}, \tilde{\theta}\right)$ to $\left(g^{L}, \theta^{L}\right)$. Q.E.D.

Proof of Proposition 4. Consider the same class of distributions of preference types than in Proposition 2, replacing condition (b) by $N_{A}>\max \left\{F_{P}\left(g^{M}\right), N_{P}-\right.$ $\left.F_{P}\left(g^{L M}\right)\right\}$. Also, define $\bar{\theta}$ as follows

$$
\bar{\theta} \equiv \max \left\{0, \max _{k \in\{L, R\}}\left\{\widetilde{\theta}-\frac{\left|g^{k}-g^{M}\right|}{\left|\beta_{A}\right|}\right\}\right\} .
$$

Suppose $\theta^{M}<\widetilde{\theta}$ (which holds by condition $(i)$ ) and $\min \left\{\theta^{L}, \theta^{R}\right\}>\bar{\theta}$.

There exists a political equilibrium where $p_{1}=\left(g^{M}, 0\right)$, and $p_{2}=\left(g^{M}, 1\right)$ if at least two parties are pro-reform, and $p_{1}=p_{2}=\left(g^{M}, 0\right)$ otherwise. Moreover neither party gets a majority of votes in the election, and a coalition government is in office in the second period.

Define the following strategies and beliefs:

(i) Let $\left(\sigma_{2}, \gamma_{2}\right)$ be an equilibrium profile of strategies in the second-period policy choice game, with $\sigma_{2}^{i}\left(j^{i}\right)=r^{i}$ and $\gamma_{2}^{i}\left(\mathcal{C}_{2}, g^{M}\right)=g^{i}$ for any party $i$ and government $\mathcal{C}_{2}$.

(ii) Let the government formation be as described in the paper.

(iii) Let $\alpha$ be the profile of voting strategies described in the proof of Proposition 1 , except that for any pro-reform citizen $n$,

$$
\begin{gathered}
\begin{cases}\alpha^{n}\left(L ; g^{M}, 1\right)=1 & \text { if } g^{n} \leq g^{L M} \\
\alpha^{n}\left(M ; g^{M}, 1\right)=1 & \text { if } g^{n}>g^{L M}\end{cases} \\
\begin{cases}\alpha^{n}\left(L ; g^{M}, 0\right)=1 & \text { if } g^{n} \leq g^{M} \\
\alpha^{n}\left(R ; g^{M}, 0\right)=1 & \text { if } g^{n}>g^{M} .\end{cases}
\end{gathered}
$$

(iv) Let $\left(\sigma_{1}, \gamma_{1}\right)$ be an equilibrium profile of strategies in the first-period policy choice game, with $\sigma_{1}^{M}(\mathcal{J})=\sigma_{1}^{L}\left(A, j^{M}, j^{R}\right)=0$ and $\gamma_{1}^{M}(\mathcal{J}, 0)=g^{M}$ for all $\mathcal{J} \in\{P, A\}^{3}$.

$(v)$ Finally, let the beliefs be as described in the paper. 
The key elements of the proof that those strategies and beliefs constitute a political equilibrium closely paralell those used in the previous proofs, and are not repeated. Q.E.D. 